\title{
The performance of German Fixed-Income ETFs in the presence of the debt crisis
}

\author{
Milonas, Nikolaos T. \\ Rompotis, Gerasimos G. \\ - RECEIVED: 29 SEPTEMBER 2014 \\ ACCEPTED: 3 NOVEMBER 2014
}

\begin{abstract}
The German government bonds attract fixed income investors as a safe heaven seeking refuge from the downgraded debt of other Eurozone countries. We exploit this tendency to diagnose the performance behavior of German fixed income Exchange Traded Funds (hereafter ETFs) in line to investment opportunities facing bond investors. In a sample of 38 German bond ETFs during the period from their inception to the end of 2010, we find: 1) ETFs fail to deliver any positive excess return with respect to the market return and this persist on a quarterly basis, 2) ETFs are associated with negative alphas, 3 ) a small size and a momentum effect on bond ETF returns, and 4) a statistically significant tracking error of $0.06 \%$ which is persistent on a quarterly basis. Overall, our results provide the first empirical evidence on how German bond ETFs behave with respect to the benchmarks and imply that fixed income investors using German bond ETFs should apply allocation strategies to benefit from the size and momentum effects found.
\end{abstract}

\section{Keywords:}

ETFs, Fixed-income, Performance, German market, Debt crisis.

JEL classification:

G11, G15.

Milonas, N.T. Department of Economics of the University of Athens, Greece, Corresponding author. E-mail: nmilonas@econ.uoa.gr. (8) +00302103689442 .

Rompotis, G.G. Department of Economics of the University of Athens, Greece. E-mail: geras3238@yahoo.gr 


\title{
El rendimiento de los fondos cotizados de renta fija alemana durante la crisis de la deuda
}

\author{
Milonas, Nikolaos T. \\ Rompotis, Gerasimos G.
}

\section{Resumen}

Los bonos del Estado alemán atraen inversores en renta fija como si fueran un cielo seguro en el que se busca refugio de la degradada deuda pública de otros países de la eurozona. Se aprovecha esta tendencia para diagnosticar el rendimiento de los fondos cotizados de renta fija alemana en línea con las oportunidades de inversión de los inversores en bonos. A partir de una muestra de 38 fondos cotizados de bonos alemanes durante el periodo comprendido entre su constitución y diciembre de 2010, se encuentra que: 1) los mencionados fondos no proporcionan un rendimiento superior al del mercado, lo que persiste en una base trimestral; están asociados con alfas negativos, 3) tamaño pequeño y efecto momentum, y 4) un tracking error, estadísticamente significativo, del $0,06 \%$, persistente en una base trimestral. En general, los resultados que se obtienen constituyen la primera evidencia empírica sobre el comportamiento de los fondos cotizados de bonos alemanes en relación a los benchmarks o referencias, obteniéndose que los inversores en renta fija que negocian con ellos deberían utilizar estrategias de asignación para beneficiarse los efectos tamaño y momentum encontrados en esta investigación.

\section{Palabras clave:}

Fondos cotizados, renta fija, rendimiento, mercado alemán, crisis de la deuda. 


\section{Introduction}

Despite the drastic government intervention in the banking system, the 2008 financial crisis did not subside. It has been transmitted into the real market and reduced the world GDP significantly. The deterioration in the economy and the financial markets turned into a debt crisis that affects the European economies and threatens the stability of the world economic system.

As expected, a major blow of this debt crisis is on the investment community and especially on the bond investors holding sovereign government debt. Originally affected by credit downgrades of debt of peripheral governments like Greece, Portugal, Ireland, and Spain, at the end of 2011 they are faced with possible haircuts of debt of these countries and are squeezed by market declines in the debt of core Eurozone countries like Italy and France. Government debt is not safe anymore and there is a hunt for the riskless asset worldwide. Germany is one country whose debt has not been downgraded and behaves as the best possible investment choice at these times of debt crisis. With many investors being attracted to invest in German bonds, this paper investigates the performance behavior of one such investment choice, the German fixed income Exchange Traded Funds (ETFs).

Investors wishing to participate in the fixed-income market can choose from a series of investment vehicles to do so. One obvious option is the direct investment in the several classes of bonds tradable on exchanges worldwide. Another possibility is the traditional actively managed bond mutual funds which, however, have usually comparatively high costs due to the up-front sale charges and the relatively high cost generating implementation of the active management.

One rapidly proliferating choice in the fixed-income area is the investment in the relevant ETFs, which track the return of fixed-income securities. While the first equity-linked ETF launched in the U.S. in January 1993, ${ }^{1}$ the introduction of fixed-income ETFs took place after approximately one decade. Mazzilli et al. (2008) report that the first four U.S.listed fixed-income ETFs were launched by Barclays Global Investors on July 26, 2002. Three of them were aimed at tracking major Treasury indices while the fourth was designed to track the performance of an investment grade corporate bond index.

In general, the fixed-income ETFs are efficient and low cost investment (no acquisition and redemption fees are charged while the administrative costs are usually low due to their passive nature). This means that for investors to gain access to a wide spectrum of fixed-income instruments from money markets, sovereign and corporate bonds, covered

\footnotetext{
${ }^{1}$ The SPDRs tracking the S\&P 500 Index was the pioneer in the field.
} 
bonds, credit default swaps to as alternative underlyings such as interest rate volatility or inflation swaps. ${ }^{2}$ Whereas in an ETF investing in stock indexes, the fund is generally composed of all the stocks in the underlying index, in the case of the majority of fixedincome ETFs, optimization techniques determine the fraction of the bonds that make up the underlying index. Bond prices are relatively straightforward being a function of the risk-free rate, the coupon, the quality of the bond and the years to maturity. However, investors should bear in mind that the tracking failure is always probable while non-synchronous trading hours may also occur between the bond ETFs and their holdings.

Fixed-income ETFs are as liquid as the equity-linked ETFs. They trade just like stocks with designated sponsors ensuring a high degree of liquidity. This means that investors can buy and sell ETF shares on the stock exchange during usual trading hours. However, investors can also acquire ETFs off-exchange from dedicated OTC market makers and through any bank or savings bank as well as through asset managers upon request. In addition, bond ETFs can be intraday- and short-traded at any time throughout the trading day. A bond ETF that trades throughout the day is therefore more liquid than a bond mutual fund, which only trades once a day at its net asset value. The drawback of the continuous trading is that a broker fee is incurred when trading an ETF, much like when trading a stock.

Fixed-income ETFs are characterized by a high degree of transparency. Transparency is achieved as the net asset value of ETFs is calculated and published on a daily basis while a re-adjustable indicative net asset value (iNAV) is calculated on a minute-byminute basis by ETF custodians and third-party vendors (such as Bloomberg). ${ }^{3}$ The iNAV is calculated by taking into account the market prices of individual holdings comprising the ETF portfolio. The iNAV helps investors to receive an up-to-the-minute indication of what an ETF is worth. They compare it with their own calculations or, with bid-ask spreads to see whether an ETF is being priced fairly in the market.

The main similarity between bonds and fixed-income ETFs is that they are affected by the same factors. These factors relate to changes in interest rates and yield spreads. In contrast, the main difference between fixed-income ETFs and bonds is that ETFs usually distribute monthly dividends, which can include both interest income on the underlying bonds and capital gains, while bonds usually pay interest semi-annually. Unlike bonds, ETFs have no maturity date. Although bonds in the fund mature eventually, the proceeds are reinvested in new bonds rather than returned to investors. The only way for an ETF investor to take their principal back is to sell the shares. The price received may be either higher or lower than the purchase price initially paid for the acquisition

${ }^{2} \mathrm{~A}$ comprehensive analysis of the types of fixed-income ETFs follows in the next section.

${ }^{3}$ Most traditional collective investment schemes calculate NAV once per day or less frequently. 
of ETF shares depending on the direction of interest rates and other bond market conditions. The non-maturity and the fact that the recoverable value at the redemption can be significantly lower than the acquisition price is a serious handicap for fixed-income ETFs. Going further, ETFs trade on stock exchanges while bonds are basically bought and sold via brokerage companies. Moreover, individual investors can execute trading strategies in fixed-income ETFs that may be difficult to apply by using bonds themselves. Short selling is a typical example. The same patterns apply when bond ETFs are compared to the traditional open-ended bond mutual funds.

In this article we examine various issues concerning the performance and performance persistence of fixed-income ETFs by employing a sample of 38 iShares listed in the German market (Deutsche Boerse). The general motivation for studying fixed-income ETFs relates to the lack of sound empirical literature in this respect despite the strong increase in the popularity of this ETFs type. ${ }^{4}$ Besides, investors are attracted by their transparency, simple tradability and low costs and this resulted in tremendous growth in the assets invested in fixed-income ETF portfolios. ${ }^{5}$ In Europe, as of July 31, 2010 fixed-income ETFs held the $25 \%$ of the assets invested in European ETFs. ${ }^{6}$ The examination of German fixed-income ETFs is justified by the importance of the German market for the entire European continent while the selection of iShares is due to their own sound proliferation among investors with total assets invested in them exceeding EUR 20 billion as of December 20, 2010. ${ }^{7}$ To the best of our knowledge, this is the first study dealing with the German fixed-income ETFs.

The findings of our article are summarized as follows: We find no significant difference between the raw return and risk of ETFs and underlying indexes. Regarding the pricing mechanism of ETFs, we find that the German iShares produce a significant negative alpha that can possibly be attributed to expenses incurred by the managers. The negative alpha is found by applying both a single-factor and a multi-factor regression analysis. The multi-factor analysis also indicates the existence of a sufficient small-cap effect as well as a momentum effect. Additionally, the stock market is not found to significantly affect the performance of bond ETFs. A significant tracking error amounting to $0.06 \%$ is estimated and found to be persistent on a quarterly basis. We also examined the rating of ETFs' and indexes' performance in risk-adjusted return terms and the persistence of risk-adjusted return of ETFs. The rating demonstrates that ETFs underperform the benchmarks while return is strongly persistent at the quarterly level.

\footnotetext{
${ }^{4}$ The research on European ETFs has been mainly focused on equity instruments rather than fixed-income ETF tools. For instance, Rompotis (2012) has investigated the trading behavior of the equity ETFs listed in the Swiss Stock Exchange.

${ }^{5}$ Rompotis (2010) investigates the performance and trading premium of 35 fixed-income iShares listed in the U.S. and finds that these ETFs underperform their benchmarks and trade at a persistent premium to their net asset value, which is meaningful in determining their future returns.

${ }^{6}$ Source: Deutsche Bank AG, Bloomberg; as of July 31, 2010.

${ }^{7}$ This figure derives from the summation of each ETF's assets as of December 20, 2010 in Table 1.
} 
The rest of this article is organized as follows: The types of fixed-income ETFs are described in the next section. Next the sample of ETFs adopted by this study is described followed by the descriptive statistics of return data in the sample. The methodological issues are discussed next followed by the empirical analysis. Summary and conclusions are provided in the last section.

\section{Types of fixed-income ETFs}

As long as the focus of our study is on the German market, we concentrate the description of fixed-income ETFs on the types available in European markets. ${ }^{8}$ Thus, investors who want to invest in fixed-income ETFs in the European continent have a wide range of choices described below. ${ }^{9}$

The Money market ETFs cover the overnight inter-banking money market. Given the low risk they expose their investors to, they are generally adopted by investors as an efficient means of allocating excess cash.

The Sovereign bond ETFs are based on the development of sector indices on investment grade sovereign bonds, i.e., sovereign bonds spanning across all maturities and which are rated investment grade by the rating agencies. ETFs linked to sovereign bond indices cover entire zones (e.g. Eurozone) or focus on a single region like the US, Germany or the UK. In general, ETFs investing in sovereign bonds can cover shortterm maturities (less than 5 years), medium maturities (between 5 and 10 years), and long maturities (more than 10 years).

One type of Sovereign bond ETFs are these that are linked to a short government bond index and provide the inverse exposure to the prices in the relevant bond market, i.e., they move in line with the respective bond yields. This makes them potential hedging instruments for investors wishing to position their portfolios against falling bond prices. However, it should be noted that sometimes the determination of the exact yield for fixed-income ETFs can be difficult.

The fixed-income ETFs invest in emerging markets bonds. Depending on the ETF, some may provide exposure to the foreign exchange risk of the issuing country's currency versus the ETF's currency.

\footnotetext{
${ }^{8}$ More or less, these are the types of fixed-income ETFs available worldwide.

${ }^{9}$ This analysis of fixed-income ETFs is based on information obtained from a relevant investment guide issued by Deutsche Bank concerning its own fixed-income ETFs (the so-called $\mathrm{db} x$-trackers).
} 
The inflation-linked bond ETFs aim at protecting their holders from inflation in a currency zone by having coupon and nominal payments linked to the officially published inflation index of the respective currency zone. They provide a hedge against inflation and are designed to outperform regular bonds when inflation expectation rises. In the same context, inflation-linked swap ETFs allowing investors to track the performance of inflation swaps are also available. Inflation-linked swaps are derivatives that aim to protect one party of the swap against the inflation in a currency zone by exchanging a fixed payment against a payment linked to the officially published inflation index of the respective currency zone.

The Covered bond ETFs, enable investors to trade an entire portfolio of covered bonds at a low cost. A covered bond is a corporate bond which is the recourse to a pool of assets that secures or covers the bond if the originator becomes insolvent. This enhancement typically results in the bonds being assigned very high credit ratings.

The Corporate bond ETFs provide exposure to indices on various investment grade corporate bonds. Corporate bonds are debt instruments issued by companies so as to raise money necessary for their funding needs (e.g. expansion to a new sector or a new country). Corporate bonds typically carry a higher yield and risk compared to sovereign bonds. They are available for different credit ratings and different market sectors.

The Credit default swap ETFs participate in the development of CDS indices (Credit Default Swap indices), which track the return for either the seller or the buyer of credit protection on a portfolio of reference entities. They can provide a very liquid way to access the credit market for both investment grade and sub-investment grade corporations.

Lastly, the Implied interest rate volatility ETFs are involved in the development of a so-called "hidden asset" volatility. The market for Eurozone interest rates has a liquid option market and just like options in the equity space, prices for options on interest rate swaps, the so called swaptions, imply a certain level of volatility. Market participants can position their portfolios for rising (long) or falling (short) implied volatility of Eurozone swaptions using ETFs.

\section{The sample}

The sample of the study consists of 38 iShares listed in Deutsche Boerse. All the data concerning these 38 ETFs have been found on the Deutsch version of iShares' website. The study period covers the inception of each ETF till December 20, 2010. This interval covers the collapse of Lehman Brother in September 2008, which is considered to be the inception of the global financial crisis, plus the period in which Greece entered 
into a bailout agreement with EU and IMF in April 2010, which is considered to have triggered the debt crisis in Eurozone. We choose to examine the German fixed-income ETFs up to end of 2010 because we want to evaluate their trading behavior during the period of the panic, which was instilled by the two crucial events above.

The only criterion applied for the selection of the sample's ETFs was the full trading history for at least one year before December 20, 2010. Table 1, Panel A reports the inception date of each ETF along with its age till the end of the study period. The average age of the sample just exceeds 4 years while the maximum age reaches 8 years. On the other hand, the youngest German fixed-income iShares is just 1.25 years old.

\section{Table 1. Panel A: Profiles of ETFs}

This table presents the profiles of German Fixed-Income ETFs, with each ETF's symbol, name (the tracking index can be inferred from the name), inception date, age up to December 20, 2010, expense ratio, average assets under management since the inception of each ETF up to December 20, 2010, total assets as of December 20, 2010, total growth in assets since the inception of each ETF up to December 20, 2010, and the average percentage flows.

\begin{tabular}{|c|c|c|c|c|}
\hline Symbol & Name & $\begin{array}{c}\text { Inception } \\
\text { Date }\end{array}$ & Age & $\begin{array}{l}\text { Expense } \\
\text { Ratio (\%) }\end{array}$ \\
\hline EUN4 & iShares Barclays Capital Euro Aggregate Bond & $06 / 03 / 2009$ & 1.82 & 0.25 \\
\hline EUN5 & iShares Barclays Capital Euro Corporate Bond & 06/03/2009 & 1.82 & 0.20 \\
\hline EUNR & iShares Barclays Capital Euro Corporate Bond ex-Financials & 25/09/2009 & 1.25 & 0.20 \\
\hline IBCD & iShares Markit iBoxx \$ Corporate Bond & $16 / 05 / 2003$ & 7.71 & 0.20 \\
\hline IBCS & iShares Markit iBoxx Euro Corporate Bond & $17 / 03 / 2003$ & 7.88 & 0.20 \\
\hline EXHE & iShares eb.rexx ${ }^{\circledast}$ Jumbo Pfandbriefe (DE) & $02 / 12 / 2004$ & 6.14 & 0.10 \\
\hline EUNT & iShares Barclays Capital Euro Corporate Bond 1-5 & $25 / 09 / 2009$ & 1.25 & 0.20 \\
\hline EUNS & iShares Barclays Capital Euro Corporate Bond ex-Financials 1-5 & 25/09/2009 & 1.25 & 0.20 \\
\hline SLXX & iShares Markit iBoxx $f$ Corporate Bond & $29 / 03 / 2004$ & 6.83 & 0.20 \\
\hline IUS6 & iShares Markit iBoxx Euro Covered Bond & 01/08/2008 & 2.42 & 0.20 \\
\hline IUS5 & iShares Barclays Capital Global Inflation-Linked Bond & 01/08/2008 & 2.42 & 0.25 \\
\hline EUN3 & iShares Citigroup Global Government Bond & 06/03/2009 & 1.82 & 0.20 \\
\hline EUN8 & iShares Barclays Capital Euro Government Bond 10-15 & $17 / 04 / 2009$ & 1.70 & 0.20 \\
\hline IBCN & iShares Barclays Capital Euro Government Bond 3-5 & $08 / 12 / 2006$ & 4.09 & 0.20 \\
\hline IBCM & iShares Barclays Capital Euro Government Bond 7-10 & 08/12/2006 & 4.09 & 0.20 \\
\hline IBCA & iShares Barclays Capital Euro Government Bond 1-3 & 05/06/2006 & 4.61 & 0.20 \\
\hline$\underline{I B C L}$ & iShares Barclays Capital Euro Government Bond 15-30 & 08/12/2006 & 4.09 & 0.20 \\
\hline EUN9 & iShares Barclays Capital Euro Government Bond 5-7 & $17 / 04 / 2009$ & 1.70 & 0.20 \\
\hline IBCI & iShares Barclays Capital Euro Inflation Linked Bond & 18/11/2005 & 5.16 & 0.25 \\
\hline EUN6 & iShares Barclays Capital Euro Treasury Bond 0-1 & 06/03/2009 & 1.82 & 0.20 \\
\hline EXHA & iShares eb.rexx ${ }^{\circledR}$ Government Germany (DE) & $04 / 02 / 2003$ & 7.99 & 0.16 \\
\hline EXX6 & iShares eb.rexx ${ }^{\circledR}$ Government Germany $10.5+(\mathrm{DE})$ & 28/09/2005 & 5.30 & 0.16 \\
\hline EXHD & iShares eb.rexx ${ }^{\circledR}$ Government Germany 5.5-10.5 (DE) & $11 / 06 / 2003$ & 7.64 & 0.15 \\
\hline EXVM & iShares eb.rexx ${ }^{\circledR}$ Money Market (DE) & $29 / 07 / 2008$ & 2.43 & 0.13 \\
\hline
\end{tabular}




\begin{tabular}{lllll}
\hline EXHG & iShares Markit iBoxx € Liquid Sovereigns Capped 1.5-2.5 (DE) & $11 / 07 / 2006$ & 4.51 & 0.16 \\
\hline EXHH & iShares Markit iBoxx € Liquid Sovereigns Capped 2.5-5.5 (DE) & $11 / 07 / 2006$ & 4.51 & 0.16 \\
\hline EXHB & iShares eb.rexx ${ }^{\circledR}$ Government Germany 1.5-2.5 (DE) & $11 / 06 / 2003$ & 7.64 & 0.16 \\
\hline EXHC & iShares eb.rexx ${ }^{\circledR}$ Government Germany 2.5-5.5 (DE) & $11 / 06 / 2003$ & 7.64 & 0.16 \\
\hline EXHF & iShares Markit iBoxx € Liquid Sovereigns Capped 1.5-10.5 (DE) & $11 / 07 / 2006$ & 4.51 & 0.16 \\
\hline EXHK & iShares Markit iBoxx € Liquid Sovereigns Capped 10.5+ (DE) & $11 / 07 / 2006$ & 4.51 & 0.16 \\
\hline EXHJ & iShares Markit iBoxx € Liquid Sovereigns Capped 5.5-10.5 (DE) & $11 / 07 / 2006$ & 4.51 & 0.16 \\
\hline INXG & iShares Barclays Capital Index-Linked Gilts & $01 / 12 / 2006$ & 4.11 & 0.25 \\
\hline IGLT & iShares FTSE UK All Stocks Gilt & $01 / 12 / 2006$ & 4.11 & 0.20 \\
\hline IUST & iShares Barclays Capital \$ TIPS & $08 / 12 / 2006$ & 4.09 & 0.25 \\
\hline IUSM & iShares Barclays Capital \$ Treasury Bond 7-10 & $08 / 12 / 2006$ & 4.09 & 0.20 \\
\hline IUSU & iShares Barclays Capital \$ Treasury Bond 1-3 & $02 / 06 / 2006$ & 4.62 & 0.20 \\
\hline IUS7 & iShares JPMorgan \$ Emerging Markets Bond Fund & $15 / 02 / 2008$ & 2.89 & 0.45 \\
\hline EUNH & iShares Barclays Capital Euro Treasury Bond & $17 / 04 / 2009$ & 1.70 & 0.20 \\
\hline Average & & & $\mathbf{4 . 1 2}$ & $\mathbf{0 . 2 0}$ \\
\hline Min & & $\mathbf{1 . 2 5}$ & $\mathbf{0 . 1 0}$ \\
\hline Max & & $\mathbf{7 . 9 9}$ & $\mathbf{0 . 4 5}$ \\
\hline
\end{tabular}

Also reported are administrative expenses charged by ETFs as reflected in their expense ratio. The respective average ratio is equal to $0.20 \%$ while the expense ratios range from $0.10 \%$ to $0.45 \%$. These figures verify the low cost involved in investing in fixedincome ETFs.

Going further, Table 1, Panel B lists the assets held by each ETF. The average assets of the period amount to EUR 275 million with EUR 9.96 million at the lowest, and 1.29 billion at the highest. As of the end of the study period, the average ETF held about EUR 533 million with minimum and maximum assets under management at EUR 10.3 and EUR 3,615.64 million, respectively. Quite interesting is the reported growth in assets that exceeds $2.000 \%$, on the average.

\section{Table 1. Panel B: Profiles of ETFs (continued)}

\begin{tabular}{lccrc}
\hline Symbol & $\begin{array}{c}\text { Average } \\
\text { Assets }\end{array}$ & $\begin{array}{c}\text { Assets @ } \\
\mathbf{1 2 / 2 0 / 2 0 1 0}\end{array}$ & $\begin{array}{c}\text { \% Asset } \\
\text { Growth }\end{array}$ & $\begin{array}{c}\text { \% Average } \\
\text { Flows }\end{array}$ \\
\hline EUN4 & $127,465,195.77$ & $370,735,750.88$ & $1,140.74$ & -1.794 \\
\hline EUN5 & $571,974,249.82$ & $1,047,851,109.83$ & $3,424.27$ & -4.246 \\
\hline EUNR & $58,011,374.99$ & $168,211,390.03$ & 743.81 & -2.062 \\
\hline IBCD & $275,730,973.28$ & $845,214,651.83$ & 138.92 & -1.656 \\
\hline IBCS & $1,291,044,551.93$ & $3,615,643,201.61$ & 375.01 & -1.784 \\
\hline EXHE & $717,766,506.92$ & $1,263,501,336.14$ & $1,055.68$ & -1.371 \\
\hline EUNT & $44,424,749.62$ & $71,754,890.61$ & 260.28 & -1.586 \\
\hline EUNS & $42,963,031.91$ & $112,169,438.47$ & 462.45 & -1.775 \\
\hline SLXX & $432,406,281.07$ & $1,165,904,433.34$ & 968.71 & -1.320 \\
\hline IUS6 & $35,101,293.41$ & $65,143,088.13$ & 330.52 & -2.254 \\
\hline EUS5 & $69,365,980.80$ & $156,935,681.47$ & 937.36 & -0.233 \\
\hline
\end{tabular}




\begin{tabular}{|c|c|c|c|c|}
\hline EUN8 & $14,044,749.96$ & $10,347,133.49$ & 3.50 & -1.888 \\
\hline IBCN & $230,909,241.14$ & $412,794,240.73$ & $3,644.52$ & -1.937 \\
\hline IBCM & $229,020,075.03$ & $302,944,995.68$ & $1,649.44$ & -2.235 \\
\hline IBCA & $314,255,304.38$ & $795,242,618.84$ & $1,808.18$ & -1.390 \\
\hline IBCL & $94,789,892.79$ & $134,498,399.53$ & 952.25 & -1.597 \\
\hline EUN9 & $24,983,828.52$ & $41,705,895.34$ & 317.86 & -1.742 \\
\hline IBCI & $314,318,316.22$ & $711,106,413.80$ & 2,179.92 & -1.134 \\
\hline EUN6 & $20,725,133.79$ & $12,317,118.96$ & -17.84 & -0.269 \\
\hline EXHA & $431,746,779.60$ & $813,284,965.46$ & $13,834.45$ & -1.654 \\
\hline EXX6 & $205,199,388.00$ & $143,828,731.43$ & 437.96 & -1.790 \\
\hline EXHD & $733,250,592.09$ & $746,434,067.57$ & $3,180.12$ & -1.784 \\
\hline EXVM & $825,421,817.43$ & $646,135,421.29$ & $3,150.30$ & -0.696 \\
\hline EXHG & $90,478,466.66$ & $106,956,437.85$ & 448.16 & -1.232 \\
\hline EXHH & $75,143,191.51$ & $84,848,330.56$ & 317.56 & -1.492 \\
\hline EXHB & $520,725,692.49$ & $1,626,013,186.57$ & $7,726.63$ & -1.133 \\
\hline EXHC & $578,643,443.94$ & $793,536,609.98$ & $3,545.05$ & -1.496 \\
\hline EXHF & $108,668,287.18$ & $147,412,206.28$ & 619.64 & -1.479 \\
\hline EXHK & $21,163,846.32$ & $21,048,225.66$ & -0.04 & -1.685 \\
\hline EXHJ & $182,617,663.96$ & $103,517,490.24$ & 402.30 & -1.528 \\
\hline INXG & $281,650,997.24$ & $505,695,785.77$ & $2,470.53$ & -2.566 \\
\hline IGLT & $240,003,420.26$ & $409,390,625.34$ & $4,043.31$ & -2.222 \\
\hline IUST & $365,110,719.93$ & $467,926,823.43$ & $2,849.12$ & -2.540 \\
\hline IUSM & $171,421,309.61$ & $309,576,482.53$ & $1,623.03$ & -2.891 \\
\hline IUSU & $234,005,952.05$ & $605,751,053.24$ & $1,041.38$ & -1.605 \\
\hline IUS7 & $311,960,895.95$ & $1,033,609,803.93$ & $10,216.19$ & -3.316 \\
\hline EUNH & $9,963,705.42$ & $16,823,519.26$ & 68.24 & -1.173 \\
\hline Average & $275,098,757.94$ & $532,642,388.30$ & $2,068.84$ & -1.773 \\
\hline Min & $9,963,705.42$ & $10,347,133.49$ & -17.84 & -4.246 \\
\hline Max & $1,291,044,551.93$ & $3,615,643,201.61$ & $13,834.45$ & -0.233 \\
\hline Total & & $20.240 .410 .755,29$ & & \\
\hline
\end{tabular}

Finally, the average percentage flow in the German fixed-income ETFs is estimated according to equation (1) provided by Gruber (1996) and Sirri and Tufano (1998) and shown in the last column of Table 1, Panel B.

$$
\text { Flow }_{p i, t}=\frac{N A V_{p i, t}-N A V_{p i, t-1}\left(1+R_{p i, t}\right)}{N A V_{p i, t-1}}
$$

where: $N A V_{p i, t}$ is the net asset value of ETF portfolio $i$ on day $t$ and $R_{p i, t}$ is the return of the ETF $i$ on day $t$. Data reveal an average outflow of funds from German fixed-income iShares of $-1.77 \%$ while the lowest and maximum outflows are equal to $-0.23 \%$ and $-4.25 \%$, respectively. The negative flow measures make us assume that the spectacular growth in assets managed by the ETFs of the sample is mainly the result of the increase in their prices and secondarily the injection of new money. 


\section{Descriptive statistics}

Table 2 presents the descriptive statistics of ETF and index returns. The statistics reported are the average daily return calculated in net asset value terms, the median return, the risk expressed as the standard deviation of returns, the risk to average return ratio, the extreme daily returns along with the coefficients of skewness and kurtosis.

\section{Table 2. Panel A: Descriptive statistics of returns}

This table presents the descriptive statistics of German Fixed-Income ETFs along with the corresponding descriptive statistics of the market indexes tracked by the sample's ETFs for the period 05/02/2003-20/12/2010. The descriptive statistics are the average daily return, the standard deviation of returns (risk), the risk to average return ratio, the median daily return, the extreme scores (minimum and maximum returns), which indicates the risk per one unit of return, and the Skewness and Kurtosis coefficients. $T$-test assesses the significance of the differences in returns and other statistics between ETFs and benchmarks. $N$ is the number of daily trading observations available for each ETF.

\begin{tabular}{|c|c|c|c|c|c|c|c|c|c|}
\hline \multirow[t]{2}{*}{ Symbol } & \multicolumn{2}{|c|}{$\begin{array}{c}\text { Average } \\
\text { Return (\%) }\end{array}$} & \multicolumn{2}{|c|}{$\begin{array}{c}\text { Median } \\
\text { Return (\%) }\end{array}$} & \multicolumn{2}{|c|}{ Risk (\%) } & \multicolumn{2}{|c|}{$\begin{array}{l}\text { Coefficient of } \\
\text { Variation }\end{array}$} & \multirow[t]{2}{*}{$N$} \\
\hline & ETF & Index & ETF & Index & ETF & Index & ETF & Index & \\
\hline EUN4 & 0.018 & 0.018 & 0.021 & 0.019 & 0.188 & 0.186 & 10.299 & 10.325 & 457 \\
\hline EUN5 & 0.043 & 0.043 & 0.043 & 0.036 & 0.167 & 0.171 & 3.897 & 3.995 & 457 \\
\hline EUNR & 0.021 & 0.021 & 0.013 & 0.017 & 0.153 & 0.152 & 7.419 & 7.311 & 315 \\
\hline IBCD & 0.017 & 0.017 & 0.018 & 0.018 & 0.421 & 0.441 & 24.311 & 26.685 & 1,936 \\
\hline IBCS & 0.018 & 0.019 & 0.023 & 0.021 & 0.207 & 0.205 & 11.182 & 11.504 & 1,977 \\
\hline EXHE & 0.014 & 0.014 & 0.008 & 0.009 & 0.119 & 0.118 & 8.380 & 8.648 & 1,540 \\
\hline EUNT & 0.016 & 0.017 & 0.017 & 0.013 & 0.094 & 0.096 & 5.665 & 6.039 & 315 \\
\hline EUNS & 0.018 & 0.018 & 0.019 & 0.018 & 0.097 & 0.096 & 5.393 & 5.397 & 315 \\
\hline SLXX & 0.013 & 0.013 & 0.015 & 0.019 & 0.355 & 0.351 & 26.597 & 26.758 & 1,715 \\
\hline IUS6 & 0.023 & 0.022 & 0.029 & 0.023 & 0.192 & 0.189 & 8.549 & 8.352 & 607 \\
\hline IUS5 & 0.002 & 0.003 & -0.007 & -0.008 & 0.586 & 0.587 & 168.226 & 248.951 & 607 \\
\hline EUN3 & 0.029 & 0.029 & 0.028 & 0.029 & 0.468 & 0.464 & 16.355 & 16.222 & 457 \\
\hline EUN8 & 0.019 & 0.020 & 0.037 & 0.035 & 0.316 & 0.317 & 15.774 & 16.694 & 429 \\
\hline IBCN & 0.019 & 0.020 & 0.022 & 0.018 & 0.183 & 0.184 & 9.060 & 9.471 & 1,010 \\
\hline IBCM & 0.022 & 0.023 & 0.029 & 0.025 & 0.329 & 0.329 & 14.086 & 14.651 & 1,010 \\
\hline IBCA & 0.014 & 0.015 & 0.013 & 0.012 & 0.083 & 0.083 & 5.600 & 5.973 & 1,156 \\
\hline IBCL & 0.016 & 0.017 & 0.008 & 0.004 & 0.567 & 0.565 & 33.563 & 35.410 & 1,010 \\
\hline EUN9 & 0.018 & 0.018 & 0.015 & 0.014 & 0.214 & 0.213 & 11.597 & 12.174 & 429 \\
\hline IBCI & 0.011 & 0.012 & 0.006 & 0.005 & 0.331 & 0.331 & 26.509 & 28.870 & 1,293 \\
\hline EUN6 & 0.003 & 0.003 & 0.003 & 0.002 & 0.023 & 0.019 & 6.768 & 7.157 & 457 \\
\hline EXHA & 0.017 & 0.017 & 0.017 & 0.016 & 0.193 & 0.198 & 11.256 & 11.917 & 2,006 \\
\hline EXX6 & 0.018 & 0.018 & 0.013 & 0.016 & 0.613 & 0.598 & 33.585 & 33.373 & 1,330 \\
\hline EXHD & 0.018 & 0.019 & 0.022 & 0.018 & 0.280 & 0.278 & 14.889 & 15.518 & 1,911 \\
\hline EXVM & 0.007 & 0.007 & 0.004 & 0.004 & 0.032 & 0.029 & 4.438 & 4.122 & 610 \\
\hline EXHG & 0.012 & 0.013 & 0.012 & 0.010 & 0.138 & 0.134 & 10.786 & 10.828 & 1,130 \\
\hline EXHH & 0.015 & 0.015 & 0.014 & 0.017 & 0.176 & 0.174 & 11.365 & 11.639 & 1,130 \\
\hline
\end{tabular}




\begin{tabular}{|c|c|c|c|c|c|c|c|c|c|}
\hline EXHB & 0.011 & 0.012 & 0.008 & 0.010 & 0.080 & 0.080 & 6.728 & 7.087 & 1,911 \\
\hline EXHC & 0.015 & 0.016 & 0.015 & 0.010 & 0.163 & 0.163 & 10.348 & 10.858 & 1,911 \\
\hline EXHF & 0.015 & 0.015 & 0.020 & 0.019 & 0.270 & 0.261 & 17.570 & 17.590 & 1,130 \\
\hline EXHK & 0.017 & 0.018 & 0.009 & 0.010 & 0.563 & 0.532 & 32.146 & 31.548 & 1,130 \\
\hline EXHJ & 0.015 & 0.016 & 0.021 & 0.020 & 0.301 & 0.291 & 19.123 & 19.033 & 1,130 \\
\hline INXG & 0.026 & 0.027 & 0.039 & 0.043 & 0.650 & 0.652 & 24.401 & 25.479 & 1,010 \\
\hline IGLT & 0.022 & 0.023 & 0.024 & 0.023 & 0.432 & 0.431 & 18.826 & 19.578 & 1,010 \\
\hline IUST & 0.026 & 0.027 & 0.006 & 0.009 & 0.491 & 0.488 & 17.864 & 18.565 & 1,010 \\
\hline IUSM & 0.029 & 0.030 & 0.000 & 0.000 & 0.538 & 0.540 & 18.004 & 18.586 & 1,010 \\
\hline IUSU & 0.016 & 0.017 & 0.011 & 0.010 & 0.114 & 0.115 & 6.815 & 7.150 & 1,157 \\
\hline IUS7 & 0.033 & 0.035 & 0.045 & 0.049 & 0.653 & 0.676 & 18.408 & 20.316 & 724 \\
\hline EUNH & 0.012 & 0.012 & 0.014 & 0.010 & 0.229 & 0.229 & 19.334 & 19.431 & 429 \\
\hline Average & 0.018 & 0.018 & 0.017 & 0.016 & 0.290 & 0.289 & 18.819 & 21.400 & 1,031 \\
\hline Min & 0.002 & 0.003 & -0.007 & -0.008 & 0.023 & 0.019 & 3.897 & 3.995 & 315 \\
\hline Max & 0.043 & 0.043 & 0.045 & 0.049 & 0.653 & 0.676 & 168.226 & 248.951 & 2,006 \\
\hline$t$-test & \multicolumn{2}{|c|}{$-8.673^{a}$} & \multicolumn{2}{|c|}{$1.843^{\circ}$} & \multicolumn{2}{|c|}{0.891} & \multicolumn{2}{|c|}{-1.221} & \\
\hline
\end{tabular}

${ }^{a}$ significant at the $1 \%$ level; b significant at the $5 \%$ level; ' significant at the $10 \%$ level.

Over all 38 ETFs, the average return is equal to 1.8 basis points (bp). The respective return of the underlying benchmarks is also equal to $1.8 \mathrm{bp}$. Although equal on an average, the t-test applied on returns indicates that there is a significant difference in average returns between ETFs and indexes according to which ETFs underperform the market portfolios. Regarding the median returns, the absolute difference in returns is not statistically significant.

When it comes to risk, Table 2 reports an average risk estimate for ETFs and indexes of 0.290 and 0.289 , respectively. In addition, the average risk to return ratio of ETFs is equal to 18.82 while the corresponding coefficient of indexes amounts to 21.40 . In both cases, the risk figures between ETFs and indexes are not statistically different from each other. In the same context, when the extreme return scores are considered as indicators of price volatility, Table 2, Panel B, shows that the range of these scores for ETFs and indexes is less than 3.40. All risk estimations demonstrate that the investment of German fixed-income ETFs does not put significant hazard on investors.

Table 2. Panel B: Descriptive statistics of returns (continued)

\begin{tabular}{lcccccccrr}
\hline Symbol & \multicolumn{2}{c}{ Minimum (\%) } & \multicolumn{2}{c}{ Maximum (\%) } & \multicolumn{2}{c}{ Skewness } & \multicolumn{2}{c}{ Kurtosis } & $N$ \\
\hline & ETF & Index & ETF & Index & ETF & Index & ETF & Index & \\
\hline EUN4 & -0.582 & -0.589 & 1.081 & 1.009 & 0.287 & 0.152 & 2.379 & 1.931 & 457 \\
\hline EUN5 & -0.694 & -0.722 & 0.848 & 0.585 & -0.132 & -0.272 & 2.320 & 1.661 & 457 \\
\hline EUNR & -0.481 & -0.467 & 0.485 & 0.439 & -0.089 & -0.083 & 0.334 & 0.135 & 315 \\
\hline IBCD & -6.383 & -6.048 & 2.788 & 2.856 & -2.151 & -1.489 & 34.441 & 23.633 & 1,936 \\
\hline IBCS & -1.296 & -1.290 & 0.883 & 0.922 & -0.378 & -0.365 & 1.881 & 1.879 & 1,977 \\
\hline EXHE & -0.803 & -0.787 & 0.521 & 0.509 & -0.178 & -0.153 & 2.595 & 2.488 & 1,540 \\
\hline EUNT & -0.489 & -0.507 & 0.301 & 0.354 & -0.474 & -0.424 & 2.218 & 2.545 & 315 \\
\hline EUNS & -0.358 & -0.357 & 0.310 & 0.275 & -0.073 & -0.077 & 0.558 & 0.448 & 315 \\
\hline
\end{tabular}




\begin{tabular}{|c|c|c|c|c|c|c|c|c|c|}
\hline SLXX & -2.648 & -2.552 & 1.677 & 1.425 & -0.605 & -0.584 & 3.918 & 3.417 & 1,715 \\
\hline IUS6 & -0.731 & -0.767 & 0.874 & 0.801 & -0.041 & -0.097 & 1.359 & 1.056 & 607 \\
\hline IUS5 & -2.299 & -2.290 & 3.672 & 3.636 & 0.613 & 0.479 & 5.549 & 4.639 & 607 \\
\hline EUN3 & -1.455 & -1.456 & 3.679 & 3.689 & 0.905 & 0.900 & 8.096 & 8.439 & 457 \\
\hline EUN8 & -1.211 & -1.213 & 1.142 & 1.144 & -0.183 & -0.166 & 0.661 & 0.651 & 429 \\
\hline IBCN & -0.904 & -0.915 & 0.780 & 0.821 & -0.107 & -0.073 & 2.329 & 2.436 & 1,010 \\
\hline IBCM & -1.196 & -1.194 & 1.296 & 1.291 & 0.007 & 0.006 & 0.935 & 0.946 & 1,010 \\
\hline IBCA & -0.459 & -0.476 & 0.528 & 0.526 & 0.096 & 0.127 & 5.251 & 5.584 & 1,156 \\
\hline IBCL & -2.965 & -2.809 & 2.278 & 2.276 & -0.125 & -0.113 & 2.098 & 1.987 & 1,010 \\
\hline EUN9 & -0.671 & -0.670 & 0.651 & 0.651 & -0.152 & -0.150 & 0.336 & 0.359 & 429 \\
\hline IBCI & -2.110 & -2.111 & 1.780 & 1.783 & -0.159 & -0.169 & 3.777 & 3.749 & 1,293 \\
\hline EUN6 & -0.109 & -0.098 & 0.280 & 0.218 & 3.780 & 2.661 & 50.363 & 38.173 & 457 \\
\hline EXHA & -0.944 & -0.951 & 0.884 & 0.797 & -0.196 & -0.270 & 1.692 & 1.742 & 2,006 \\
\hline EXX6 & -4.035 & -3.941 & 3.049 & 3.002 & -0.198 & -0.215 & 3.778 & 3.394 & 1,330 \\
\hline EXHD & -1.290 & -1.272 & 1.215 & 1.131 & -0.125 & -0.137 & 1.622 & 1.413 & 1,911 \\
\hline EXVM & -0.197 & -0.190 & 0.213 & 0.206 & 0.970 & 1.050 & 13.429 & 16.797 & 610 \\
\hline EXHG & -0.759 & -0.707 & 2.990 & 2.850 & 8.517 & 8.030 & 194.847 & 183.417 & 1,130 \\
\hline $\mathrm{EXHH}$ & -0.789 & -0.782 & 2.370 & 2.324 & 1.931 & 1.837 & 29.300 & 28.302 & 1,130 \\
\hline EXHB & -0.442 & -0.483 & 0.466 & 0.458 & -0.044 & -0.168 & 4.468 & 4.486 & 1,911 \\
\hline EXHC & -0.869 & -0.883 & 0.787 & 0.667 & -0.129 & -0.218 & 2.439 & 2.561 & 1,911 \\
\hline EXHF & -1.005 & -0.988 & 2.400 & 2.279 & 0.578 & 0.511 & 6.390 & 5.701 & 1,130 \\
\hline EXHK & -3.424 & -2.542 & 3.833 & 2.248 & -0.040 & -0.093 & 5.243 & 1.958 & 1,130 \\
\hline EXHJ & -1.221 & -1.026 & 2.394 & 2.303 & 0.389 & 0.352 & 4.456 & 3.915 & 1,130 \\
\hline INXG & -2.786 & -2.793 & 2.540 & 2.527 & -0.354 & -0.359 & 1.466 & 1.472 & 1,010 \\
\hline IGLT & -1.866 & -1.864 & 2.756 & 2.744 & 0.124 & 0.128 & 2.793 & 2.808 & 1,010 \\
\hline IUST & -2.867 & -2.884 & 3.416 & 3.433 & -0.021 & -0.083 & 5.863 & 5.392 & 1,010 \\
\hline IUSM & -2.464 & -2.482 & 3.740 & 3.756 & 0.143 & 0.165 & 3.395 & 3.469 & 1,010 \\
\hline IUSU & -0.796 & -0.810 & 0.674 & 0.673 & -0.232 & -0.251 & 6.026 & 6.095 & 1,157 \\
\hline IUS7 & -6.245 & -6.785 & 5.096 & 4.005 & -1.511 & -2.341 & 32.626 & 33.820 & 724 \\
\hline EUNH & -0.694 & -0.717 & 1.797 & 1.788 & 0.887 & 0.862 & 8.287 & 8.305 & 429 \\
\hline Average & -1.593 & -1.564 & 1.749 & 1.642 & 0.303 & 0.234 & 12.093 & 11.084 & 1,031 \\
\hline Min & -6.383 & -6.785 & 0.213 & 0.206 & -2.151 & -2.341 & 0.334 & 0.135 & 315 \\
\hline Max & -0.109 & -0.098 & 5.096 & 4.005 & 8.517 & 8.030 & 194.847 & 183.417 & 2,006 \\
\hline$t$-test & \multicolumn{2}{|c|}{-0.988} & \multicolumn{2}{|c|}{$2.147^{\mathrm{b}}$} & \multicolumn{2}{|c|}{$1.615^{c}$} & \multicolumn{2}{|c|}{$1.926^{c}$} & \\
\hline
\end{tabular}

${ }^{\mathrm{a}}$ significant at the $1 \%$ level; ${ }^{\mathrm{b}}$ significant at the $5 \%$ level; ${ }^{\mathrm{c}}$ significant at the $10 \%$ level.

Moreover, the average skewness estimates show that ETF returns are more skewed than the tracking indexes. However, skewness does not seem to be a problem either for ETFs or the indexes. On the other hand, the coefficients of kurtosis reveal that the return distributions of ETFs and indexes are leptokurtic.

\section{Methodological issues}

In this section, we describe the methodological issues concerning this study. We examine the pricing of German fixed-income ETFs both via single-factor and multi-factor regression analysis, the performance evaluation of ETFs and indexes using risk-ad- 
justed returns, the persistence in ETFs' risk-adjusted return, the calculation of ETFs' tracking error, and its persistence.

\subsection{Single-factor regression analysis}

We perform the single-index regression analysis as in equation (2):

$$
R_{p i}-R_{f}=\alpha_{p i}+\beta_{p i}\left(R_{m}-R_{f}\right)+\varepsilon_{p i}
$$

where: $R_{p i}$ denotes the daily portfolio's return for the ith ETF, $R_{m}$ is the return of the market portfolio represented by each ETF's underlying index, $R_{f}$ is the risk-free rate as estimated by the 12-month Euribor, and $\varepsilon_{p i}$ is the residual error of the regression. The $\alpha_{p i}$ coefficient is the alpha used to measure the excess return an ETF can achieve above the market return when risk is taken into account. Since the structure of fixed-income ETFs, aims at replicating the performance of the benchmarks, the alpha coefficients are not expected to be positive. On the contrary, given the fact that ETF return is calculated net of administrative expenses, we expect negative and significant alphas.

The beta $(\beta)$ coefficient in equation (2) is an estimate for the ETF systematic risk. If we take into account the passive nature of the examined ETFs, beta is indicative of the adopted replication strategy. A significant deviation between ETFs' beta and unity will indicate the departure from a full replication strategy and the implementation of optimization techniques.

\subsection{Multi-factor regression analysis}

Apart from the single-index model, the literature on traditional mutual funds has indicated that fund returns can also be explained by some additional factors (refer for instance to Fama and French,1993; Blake et al., 1993; and Carhart, 1997). Following the literature on mutual funds, we apply a four-factor performance analysis of German fixed-income ETFs as in equation (3):

$$
R_{p i}-R_{f}=\alpha_{p i}+\beta_{p i}\left(R_{m}-R_{f}\right)+S_{p i} S M B+w_{p i} W M L+d_{p i} S t R e t+\varepsilon_{p i}
$$

where: $R_{p i}, R_{m}, R_{f}$ and $\varepsilon_{p i}$ are defined as above.

SMB stands for the "small" (assets under management) minus the "large" ETFs of the sample. It is calculated by following the methodology applied by Silva et al. (2005) for the classification of European bond funds between winners and losers. More specifically, the authors consider funds with returns above and below the median return as winners and losers, respectively. Similarly, we consider large those sample ETFs 
having average assets that are higher than the median average asset. ETFs with average assets lower than the median average assets are considered small. Finally, the $S M B$ index is calculated by subtracting the average daily return of large ETFs from the corresponding average return of small ETFs.

The $W M L$ variable represents the non-weighted return of winners minus losers portfolio calculated using the returns of the sample's ETFs. The WML index is prepared in the same way as the $S M B$ index. The last variable included in our model, the StRet, concerns the German stock market. The DAX index is used as a proxy for the German stock market. We include this variable following the approach of Maag and Zimmermann (2000) who studied the performance of German bond mutual funds. ${ }^{10}$

In the case of equity mutual funds, the size effect implies that the firms with small market capitalization table returns that, on average, are significantly superior to those of large firms. In our case, we also assume that the size of fixed-income ETFs may exert an inverse effect on their returns. That is, the small ETFs have greater returns than the large ETFs. Furthermore, to the extent that winners repeat their performance, we expect a positive coefficient for the momentum factor included in the model. Finally, Maag and Zimmermann (2000) find that the stock returns do affect the pricing of German bond mutual funds (without, however, clarifying whether the impact of stock prices on bond funds is positive or negative). However, because bond prices tend to move opposite to stocks, we expect the coefficient for the DAX index to be negative. The rationale behind this tendency is that when the economy begins to reheat, people move money out of riskier assets in favor of the investments that are considered safer. Since bonds are generally thought to be safer than stocks, bond prices tend to rise while stock prices are falling.

\subsection{Risk-adjusted returns and persistence}

We compare the German fixed-income ETFs to the tracking indexes in terms of riskadjusted performance. We do so by estimating three alternative types of risk-adjusted return. The first one is the well-known Sharpe ratio in equation (4):

$$
S_{p i}=\frac{\bar{R}_{p i}-\bar{R}_{f}}{\sigma_{p i}}
$$

where: $\bar{R}_{p i}$ denotes the average daily return for the ith ETF or the corresponding index. $\bar{R}_{f}$ is the average daily risk-free rate expressed by the 12 -month Euribor, and $\sigma_{p i}$ is the standard deviation of ETF's or index's $i$ return. The Sharpe ratio divides

\footnotetext{
${ }^{10}$ Instead of using DAX, Maag and Zimmermann (2000) use the DAFOX index which covers all the quoted stocks traded at the Deutsche Boerse in Frankfurt. In any case, the DAX index employed by us is representative enough of the German stock market.
} 
the excess return by risk to determine how well the return of a portfolio compensates investors for one unit of risk.

The second ratio is the Sortino ratio shown in equation (5):

$$
\operatorname{Sor}_{p i}=\frac{\bar{R}_{p i}-\bar{R}_{f}}{\sigma_{p i, d}}
$$

where: $\bar{R}_{p i}$ and $\bar{R}_{f}$ are defined as above and $\sigma_{p i, d}$ is the standard deviation of ETFs' or index's $i$ negative returns. The Sortino ratio differentiates between good and bad volatility in the Sharpe ratio. This differentiation allows the calculation of risk-adjusted return to provide a performance measure of ETFs or indexes without penalizing them for positive price changes. Like the Sharpe ratio, the higher the Sortino ratio, the better the performance of a fund or a benchmark.

The third risk-adjusted return measure we use to evaluate the performance of ETFs and indexes is the Treynor ratio shown in equation (6):

$$
T_{p i}=\frac{\bar{R}_{p i}-\bar{R}_{f}}{\beta_{p i}}
$$

where: $\bar{R}_{p, i}$ and $\bar{R}_{f}$ are defined as above and $\beta_{p i}$ is the systematic risk of ETF or index $i$. By definition, the beta of indexes is equal to 1 . Similarly to Sharpe and Sortino ratios, the higher the Treynor ratio, the better the performance.

Besides the estimation of the risk-adjusted performance of ETFs and indexes we also test their persistence. Persistence is of high importance in the relating mutual fund literature, both in the cases of equity and bond funds. In our study, we assess shortterm performance persistence of German fixed-income ETFs following the approach of Hendricks et al. (1993) and Bollen and Busse (2004) who employ quarterly performance measurements. Regarding of the type of performance used for evaluating persistence, we follow Huij and Derwall (2008), who employ Sharpe ratio and prepare a time-series for each ETF consisting of its quarterly Sharpe ratios. In the end, we examine persistence via the following time-series regression model (7):

$$
\text { Sharpe }_{p i, t}=\kappa_{p i}+\lambda_{p i} \text { Sharpe }_{p i, t-1}+\varepsilon_{p i}
$$

where: Sharpe $e_{p i, t}$ represents the risk-adjusted return of the ith ETF in quarter $t$. The $\lambda$ coefficient is the indicator of short-term persistence. A positive and significant $\lambda$ will indicate that the risk-adjusted return of the ith ETF in one quarter can predict its performance in the following quarter. The closer coefficient $\lambda$ is to unity, the stronger the performance persistence. 


\subsection{Tracking Error's measurement and persistence}

The deviation of an index fund's performance from its corresponding index is defined as "tracking error." In our study, we apply three alternative methods for estimating tracking error. The first, and most commonly used, method, $T E_{1, P}$, computes the standard deviation of return differences between ETFs and their indexes. The estimation of this tracking error is presented in equation (8):

$$
T E_{1, P}=\sqrt{\frac{1}{n-1}} \sum_{t=1}^{n}\left(e_{p t}-\bar{e}_{p}\right)^{2}
$$

where: $e_{p t}$ is the difference of returns on day $t$ and $\bar{e}_{p}$ is the average return's difference over $n$ days.

The second method, $T E_{2, P}$, is defined as the standard error of performance regression (2).

The first two methods are standard in the relevant literature and treat tracking errors in the same way irrespective of whether they are positive or negative. Yet, most investors prefer ETFs that produce positive tracking errors (since these enhance realized returns) and mind about the negative tracking errors. To accommodate for this reasoning, we follow Milonas and Rompotis (2010), who employ a non-standard method for computing tracking error, $T E_{3, P}$, which is based on a semivariance analysis of the return differences between ETFs and indexes. This analysis is applied as follows:

For each ETF we identify the observations concerning negative excess returns with respect to the return of the index discarding observations equal to zero or positive. We then sum up all the squared negative excess returns and divide the sum by the number of observations with negative excess returns minus 1 . Semivariance-based analysis $(S V A)$ is represented by the following formula (9):

$$
S V A=\frac{\sum X_{E F T}<X_{I N D E X}\left(X_{E F T}-X_{I N D E X}\right)^{2}}{n-1}
$$

where: $X_{E F T}$ is the return of ETF, $X_{I N D E X}$ represents the return of the index and $\mathrm{n}$ is the number of negative excess returns. In the last step, we estimate $T E_{3, P}$ as the positive square root of equation (9). This tracking error relates to the so-called semideviation or semi standard deviation and represents the downside risk ETF investors run. If $T E_{3, P}$ is higher than $T E_{1, P}$, we will infer that the first method underestimates the actual tracking error of ETFs.

Apart from computing tracking error, we also examine its persistence. Similarly to the case of performance persistence, we calculate the tracking error for each ETF over a 
quarterly time interval creating of a relevant time-series with quarterly tracking errors for each distinct ETF in the sample.

We use the first estimate of tracking error to run regression (10) because it is the most commonly applied method in the relevant literature on index funds and ETFs. Furthermore, Milonas and Rompotis (2010) find no significant differences in tracking error computations among the various methods they perform. Based on these findings, we assume that this will be the case for German bond ETFs too and consider as assessing tracking error's persistence the first method adequate.

We evaluate the short-term persistence in ETFs' tracking error applying the time-series regression model (10):

$$
T E_{p i, t}=\mu_{p i}+\xi_{p i} T E_{p i, t-1}+\varepsilon_{p i}
$$

where: $T E_{p i, t}$ represents the tracking error of the ith ETF in quarter $t$. The $\xi$ coefficient is indicative of quarterly persistence. If the model's $\xi$ coefficient is positive and significant, tracking error will be considered persistent at the short-term level.

\section{Empirical results}

\subsection{Single-factor regression analysis}

Table 3 reports the estimates of the single-index regression analysis employed for explaining the performance of German fixed-income ETFs. In particular, presented in the table are the alpha and beta estimates of the model, along with their $t$-statistics, the $R$-square, and the number of daily observations available for each ETF. We point out that in the case of alphas, $t$-tests show the difference of estimates from zero whereas the relevant $t$-tests on beta estimates evaluate the difference of coefficients from unity.

\section{Table 3. Single-factor performance regression results}

This table presents the results of German Fixed-Income ETFs performance regression for the period 05/02/2003-20/12/2010 when the daily excess return of each ETF is regressed on the excess return of its underlying index. The risk-free rate used for the calculation of excess return is the 12-month Euribor. T-test relating to model's $\alpha$ assesses the statistical difference of alphas from zero. $T$-test concerning model's $\beta$ evaluates the difference of betas from unity. $R$-square assesses the explanatory power of regression. $N$ is the number of daily trading observations available for each ETF. 


\begin{tabular}{|c|c|c|c|c|c|c|}
\hline Symbol & $\alpha$ & $t$-test & $\beta$ & $t$-test & $R^{2}$ & $N$ \\
\hline EUN4 & -0.002 & -1.102 & $0.965 a$ & -3.491 & 0.952 & 457 \\
\hline EUN5 & -0.002 & -0.708 & 0.934 & -1.271 & 0.833 & 457 \\
\hline EUNR & -0.001 & -0.707 & $0.971^{\mathrm{b}}$ & -2.549 & 0.960 & 315 \\
\hline IBCD & $-0.012^{\mathrm{b}}$ & -2.078 & $0.918^{\mathrm{a}}$ & -3.014 & 0.771 & 1,936 \\
\hline IBCS & $-0.004^{a}$ & -3.671 & $0.973^{a}$ & -2.969 & 0.964 & 1,977 \\
\hline EXHE & $-0.006^{a}$ & -4.304 & $0.965^{a}$ & -5.461 & 0.935 & 1,540 \\
\hline EUNT & -0.002 & -1.160 & $0.972^{\circ}$ & -1.619 & 0.907 & 315 \\
\hline EUNS & -0.002 & -1.171 & $0.964^{b}$ & -2.445 & 0.930 & 315 \\
\hline SLXX & $-0.003^{b}$ & -2.470 & $0.981^{\mathrm{a}}$ & -4.139 & 0.984 & 1,715 \\
\hline IUS6 & -0.004 & -1.392 & $0.953^{b}$ & -2.111 & 0.933 & 607 \\
\hline IUS5 & -0.002 & -0.529 & 0.995 & -0.534 & 0.987 & 607 \\
\hline EUN3 & -0.002 & -0.363 & $0.954^{a}$ & -3.707 & 0.928 & 457 \\
\hline EUN8 & -0.002 & -0.662 & 0.990 & -1.341 & 0.976 & 429 \\
\hline IBCN & -0.001 & -1.098 & 0.998 & -0.442 & 0.986 & 1,010 \\
\hline IBCM & -0.002 & -1.454 & $0.992^{b}$ & -2.117 & 0.985 & 1,010 \\
\hline IBCA & $-0.001^{b}$ & -2.589 & 0.998 & -0.879 & 0.993 & 1,156 \\
\hline $\mathrm{IBCL}$ & -0.002 & -1.051 & $0.993^{a}$ & -2.322 & 0.990 & 1,010 \\
\hline EUN9 & -0.002 & -1.003 & $0.977^{\mathrm{a}}$ & -2.356 & 0.960 & 429 \\
\hline IBCI & $-0.003^{c}$ & -1.739 & $0.990^{\mathrm{b}}$ & -2.544 & 0.980 & 1,293 \\
\hline EUN6 & $-0.008^{a}$ & -4.503 & $0.899^{a}$ & -4.135 & 0.740 & 457 \\
\hline EXHA & $-0.012^{\mathrm{a}}$ & -4.653 & $0.916^{a}$ & -8.150 & 0.797 & 2,006 \\
\hline EXX6 & $-0.008^{c}$ & -1.836 & $0.945^{a}$ & -2.650 & 0.937 & 1,330 \\
\hline EXHD & $-0.013^{a}$ & -4.599 & $0.905^{a}$ & -10.268 & 0.834 & 1,911 \\
\hline EXVM & $-0.005^{a}$ & -4.418 & $0.955^{\mathrm{a}}$ & -5.057 & 0.949 & 610 \\
\hline EXHG & $-0.005^{a}$ & -4.539 & $0.968^{a}$ & -4.622 & 0.983 & 1,130 \\
\hline EXHH & $-0.003^{a}$ & -3.233 & $0.981^{\mathrm{a}}$ & -4.450 & 0.978 & 1,130 \\
\hline EXHB & $-0.009^{a}$ & -5.734 & $0.941^{\mathrm{a}}$ & -7.195 & 0.885 & 1,911 \\
\hline EXHC & $-0.012^{\mathrm{a}}$ & -6.183 & $0.915^{\mathrm{a}}$ & -9.457 & 0.844 & 1,911 \\
\hline EXHF & $-0.010^{b}$ & -2.559 & $0.939^{a}$ & -3.153 & 0.937 & 1,130 \\
\hline EXHK & $-0.016^{b}$ & -2.015 & $0.898^{a}$ & -2.374 & 0.902 & 1,130 \\
\hline EXHJ & $-0.008^{a}$ & -2.796 & $0.947^{\mathrm{a}}$ & -2.804 & 0.955 & 1,130 \\
\hline INXG & -0.001 & -0.942 & 1.000 & 0.097 & 0.997 & 1,010 \\
\hline IGLT & $-0.002^{\circ}$ & -1.722 & $0.995^{b}$ & -2.318 & 0.996 & 1,010 \\
\hline IUST & -0.004 & -0.970 & 0.982 & -1.306 & 0.975 & 1,010 \\
\hline IUSM & -0.002 & -0.670 & 0.994 & -1.325 & 0.982 & 1,010 \\
\hline IUSU & $-0.002^{b}$ & -1.739 & 0.993 & -1.029 & 0.972 & 1,157 \\
\hline IUS7 & -0.002 & -0.212 & 1.006 & 0.187 & 0.948 & 724 \\
\hline EUNH & -0.001 & -0.497 & $0.991^{\circ}$ & -1.680 & 0.987 & 429 \\
\hline Average & -0.005 & -2.186 & 0.964 & -3.079 & 0.936 & 1,031 \\
\hline Min & -0.016 & -6.183 & 0.898 & -10.268 & 0.740 & 315 \\
\hline Max & -0.001 & -0.212 & 1.006 & 0.187 & 0.997 & 2,006 \\
\hline$t$-test & $-6.940^{a}$ & & $-7.012^{\mathrm{a}}$ & & & \\
\hline
\end{tabular}

${ }^{a}$ significant at the $1 \%$ level; ${ }^{b}$ significant at the $5 \%$ level; ${ }^{c}$ significant at the $10 \%$ level.

According to Table 3 results, the average ETF of the sample displays a negative alpha of -0.005 , which is statistically significant at the $1 \%$ level. Moreover, the individual alpha estimates are negative while the majority of them (21 out 38), are significant 
at the $10 \%$ level or better. Given the fact that the daily returns of ETFs have been calculated in net asset value terms, that is, free of administrative expenses, both the negative sign and the high statistical significance of alphas are not surprising and can be attributed to the impact of expenses. ${ }^{11}$ In addition, given the passive nature of the examined ETFs, a positive and significant alpha would be the result either of luck or a more active management of the ETFs.

When it comes to systematic risk, Table 3 shows an average beta that is equal to 0.964, significantly different from unity. This is the case for the individual ETFs as well. In particular, 10 out of 28 estimates are not statistically different from unity. In absolute terms, all the individual betas are close to unity (the lowest beta is equal to 0.898 ). Yet, both the average beta of the sample and the individual beta reflect a slight departure from a full replication strategy and indicate that the ETF managers perform selection techniques to enhance the tracking of the underlying indexes. $^{12}$

Finally, the high $R$-square values suggest that the single factor model explains well the performance of German fixed income ETFs. The model is adequate for passively managed portfolios. However, this might not be the case for the actively managed funds which seek to outperform the market and not simply to replicate it.

\subsection{Multi-factor regression analysis}

Besides, the single-index regression model, we estimated a multi-factor analysis using three other factors that can explain the performance of German bond ETFs, namely a size factor, a momentum factor and the stock market return. The results of the regression model (3) are shown in Table 4. This table includes the estimates of model's coefficients, the $t$-statistics, the $R$-square and the available observations for each ETF. Similarly to the single-index model's results, the average alpha is negative and equal to -0.008 , statistically significant at the $1 \%$ level. No individual alpha is positive while 26 out of 38 individual alphas are statistically significant. Therefore, we can infer that the selection techniques implied by the departure from a full replication strategy found in the previous section, are just to enhance the replication of the benchmarks' return and not to enable the fixed-income ETF managers to produce any abnormal returns with respect to the market returns.

\footnotetext{
"The application of the model with trading data, which may be inflated by the amount of expenses (this would be verified if ETFs traded at a premium to their NAV as Rompotis (2010) demonstrated in the case of U.S. bond ETFs), would verify our assertion that the negative alpha can be attributed to expenses. If a positive alpha was provided, then it would be inferred that the impact of expenses on returns results in the generation of negative alphas. A cross-sectional regression of such alphas and expenses ratio may also verify our claim. However, we do not have available any trading data for the German fixed-income ETFs.

${ }^{12}$ As mentioned in a previous section of the study, selection techniques are standard practice for the managers of fixed-income ETFs.
} 
Table 4. Multi-factor performance regression results

This table presents the results of German Fixed-Income ETFs performance regression for the period 05/02/2003-20/12/2010 when the daily excess return of each ETF is regressed on the excess return of the underlying index and the returns of a "small minus large" fixed-income ETFs index, a "winners minus losers" fixed-income ETFs, and $D A X$ Index. T-test relating to model's $\alpha, s, w$ and $d$ assesses the statistical difference of the estimates from zero. $T$-test concerning model's $\beta$ evaluates the difference of betas from unity. $R$-square assesses the explanatory power of regression. $N$ is the number of daily trading observations available for each ETF.

\begin{tabular}{|c|c|c|c|c|c|c|c|c|c|c|c|c|}
\hline Symbol & $\alpha$ & $t$-test & $\beta$ & $t$-test & $s$ & $t$-test & $w$ & $t$-test & $d$ & $t$-test & $R^{2}$ & $N$ \\
\hline UN4 & $-0.004^{\circ}$ & -1.897 & $0.933^{\mathrm{a}}$ & -4.470 & $0.049^{b}$ & 2.251 & $0.050^{\mathrm{b}}$ & 2.460 & 0.000 & -0.324 & 0.953 & 457 \\
\hline EUN5 & -0.004 & -1.252 & $0.883^{\circ}$ & -1.689 & $0.081^{c}$ & 1.676 & $0.097^{b}$ & 2.308 & 0.000 & -0.109 & 0.839 & 457 \\
\hline EUNR & -0.001 & -0.661 & $0.973^{c}$ & -1.621 & -0.018 & -0.944 & 0.004 & 0.141 & -0.001 & -0.321 & 0.960 & 315 \\
\hline IBCD & $-0.011^{c}$ & -1.927 & $0.917^{a}$ & -3.027 & $-0.067^{c}$ & -1.714 & $-0.173^{a}$ & -2.946 & -0.006 & -1.107 & 0.775 & 1,936 \\
\hline IBCS & $-0.006^{a}$ & -4.153 & $0.962^{\mathrm{a}}$ & -3.357 & 0.000 & 0.001 & $0.047^{a}$ & 3.273 & -0.001 & -0.843 & 0.965 & 1,977 \\
\hline EXHE & $-0.007^{a}$ & -4.613 & $0.955^{a}$ & -6.185 & -0.006 & -0.832 & $0.030^{a}$ & 3.278 & 0.000 & -0.561 & 0.936 & 1,540 \\
\hline EUNT & -0.001 & -0.612 & 0.987 & -0.610 & -0.022 & -1.254 & -0.021 & -1.000 & 0.000 & -0.203 & 0.908 & 315 \\
\hline EUNS & -0.002 & -0.837 & 0.970 & -1.540 & -0.023 & -1.511 & -0.007 & -0.352 & -0.001 & -0.862 & 0.931 & 315 \\
\hline SLXX & $-0.003^{b}$ & -2.410 & $0.980^{\mathrm{a}}$ & -4.000 & -0.007 & -1.038 & 0.000 & -0.010 & -0.002 & -1.526 & 0.984 & 1,715 \\
\hline IUS6 & $-0.008^{b}$ & -2.363 & $0.912^{b}$ & -2.486 & 0.045 & 1.481 & $0.079^{a}$ & 2.790 & $-0.002^{c}$ & -1.625 & 0.936 & 607 \\
\hline IUS5 & -0.003 & -0.905 & 0.989 & -1.171 & $0.035^{c}$ & 1.837 & $0.034^{\circ}$ & 1.672 & 0.001 & 0.813 & 0.987 & 607 \\
\hline EUN3 & -0.006 & -1.100 & $0.902^{\mathrm{a}}$ & -5.803 & $0.208^{a}$ & 3.702 & $0.243^{a}$ & 3.465 & $0.010^{\mathrm{b}}$ & 2.162 & 0.931 & 457 \\
\hline EUN8 & -0.003 & -1.248 & $0.951^{\mathrm{a}}$ & -4.004 & $0.113^{a}$ & 3.502 & $0.059^{b}$ & 2.200 & -0.003 & -1.266 & 0.977 & 429 \\
\hline IBCN & $-0.002^{c}$ & -1.704 & 0.995 & -1.069 & -0.001 & -0.209 & $0.023^{a}$ & 3.567 & 0.000 & 0.215 & 0.987 & 1,010 \\
\hline BCM & $-0.004^{a}$ & -2.902 & $0.978^{a}$ & -3.798 & 0.015 & 1.392 & $0.055^{a}$ & 4.426 & 0.000 & -0.421 & 0.985 & 1,010 \\
\hline IBCA & $-0.001^{b}$ & -2.458 & 0.998 & -0.559 & $-0.005^{a}$ & -2.746 & $0.009^{a}$ & 3.708 & 0.000 & 0.139 & 0.993 & 1,156 \\
\hline IBCL & $-0.004^{c}$ & -1.943 & $0.982^{a}$ & -3.172 & 0.031 & 1.534 & $0.052^{\mathrm{a}}$ & 3.168 & 0.000 & -0.327 & 0.990 & 1,010 \\
\hline UN9 & $-0.006^{a}$ & -2.830 & $0.905^{a}$ & -6.401 & $0.110^{a}$ & 4.811 & $0.134^{a}$ & 4.961 & -0.002 & -0.982 & 0.964 & 429 \\
\hline IBCI & $-0.003^{b}$ & -2.252 & $0.986^{a}$ & -3.216 & 0.004 & 0.461 & $0.032^{b}$ & 2.669 & -0.001 & -0.945 & 0.980 & 1,293 \\
\hline EUN6 & $-0.027^{a}$ & -7.919 & $0.615^{\mathrm{a}}$ & -7.809 & $0.009^{c}$ & 1.609 & $-0.018^{c}$ & -1.959 & -0.001 & -1.590 & 0.541 & 457 \\
\hline EXHA & $-0.011^{\mathrm{a}}$ & -3.686 & $0.921^{a}$ & -5.108 & $-0.026^{c}$ & -1.753 & -0.006 & -0.148 & 0.001 & 0.616 & 0.798 & 2,006 \\
\hline EXX6 & $-0.016^{b}$ & -2.603 & $0.891^{a}$ & -2.931 & $0.205^{b}$ & 2.217 & $0.155^{c}$ & 1.745 & -0.001 & -0.096 & 0.941 & 1,330 \\
\hline $\mathrm{XHD}$ & $-0.022^{a}$ & -7.073 & $0.855^{a}$ & -12.802 & -0.024 & -1.597 & $0.225^{a}$ & 8.215 & -0.002 & -1.056 & 0.839 & 1,911 \\
\hline EXVM & $-0.005^{a}$ & -4.459 & $0.954^{\mathrm{a}}$ & -4.336 & -0.004 & -0.661 & 0.002 & 0.292 & 0.000 & 0.010 & 0.949 & 610 \\
\hline EXHG & $-0.006^{a}$ & -4.825 & $0.966^{a}$ & -4.956 & 0.005 & 0.924 & 0.007 & 1.214 & 0.000 & 0.078 & 0.983 & 1,130 \\
\hline EXHH & $-0.005^{a}$ & -3.605 & $0.971^{\mathrm{a}}$ & -4.108 & 0.017 & 1.447 & 0.007 & 0.819 & $-0.001^{c}$ & -1.801 & 0.978 & 1,130 \\
\hline EXHB & $-0.010^{a}$ & -6.763 & $0.932^{\mathrm{a}}$ & -8.159 & $-0.015^{a}$ & -2.661 & $0.033^{a}$ & 4.078 & 0.001 & & 0.886 & 1,911 \\
\hline EXHC & $-0.017^{a}$ & -7.378 & $0.888^{a}$ & -10.070 & $-0.027^{b}$ & -2.376 & $0.099^{a}$ & 5.734 & 0.000 & 0.094 & 0.848 & 1,911 \\
\hline EXHF & $-0.018^{a}$ & -3.386 & $0.886^{a}$ & -3.367 & $0.115^{\mathrm{b}}$ & 2.223 & 0.031 & 1.262 & $-0.006^{b}$ & -2.078 & 0.941 & 1,130 \\
\hline EXHK & $-0.043^{a}$ & -3.118 & $0.721^{\mathrm{a}}$ & -3.241 & $0.796^{a}$ & 3.197 & $0.244^{a}$ & 2.911 & -0.004 & -1.068 & 0.924 & 1,130 \\
\hline EXHJ & $-0.016^{a}$ & -3.064 & $0.895^{a}$ & -3.021 & $0.136^{b}$ & 2.480 & $0.043^{b}$ & 2.219 & $-0.003^{c}$ & -1.743 & 0.958 & 1,130 \\
\hline INXG & -0.001 & -1.188 & 0.998 & -0.831 & 0.008 & 1.014 & 0.009 & 0.820 & -0.001 & -1.106 & 0.997 & 1,010 \\
\hline IGLT & $-0.002^{c}$ & -1.891 & $0.994^{b}$ & -2.365 & 0.006 & 0.898 & 0.004 & 0.418 & 0.000 & -0.538 & 0.996 & 1,010 \\
\hline IUST & $-0.007^{c}$ & -1.895 & $0.964^{b}$ & -2.472 & 0.015 & 0.551 & $0.123^{a}$ & 3.121 & 0.000 & -0.099 & 0.975 & 1,010 \\
\hline IUSM & -0.004 & -1.562 & $0.983^{a}$ & -2.812 & 0.013 & 0.761 & $0.077^{a}$ & 3.155 & 0.001 & 0.429 & 0.982 & 1,010 \\
\hline IUSU & -0.002 & -1.430 & 0.994 & -1.053 & -0.002 & -0.486 & 0.004 & 0.611 & 0.000 & 1.058 & 0.972 & 1,157 \\
\hline
\end{tabular}




\begin{tabular}{|c|c|c|c|c|c|c|c|c|c|c|c|c|}
\hline IUS7 & -0.008 & -1.027 & 0.958 & -0.844 & -0.005 & -0.114 & 0.092 & 1.237 & $0.031^{\mathrm{c}}$ & 1.784 & 0.952 & 724 \\
\hline EUNH & -0.002 & -1.149 & $0.960^{\mathrm{a}}$ & -2.777 & $0.074^{b}$ & 2.262 & 0.005 & 0.305 & -0.002 & -1.575 & 0.988 & 429 \\
\hline Average & -0.008 & -2.792 & 0.934 & -3.786 & 0.048 & 0.588 & 0.049 & 1.995 & 0.000 & -0.412 & 0.932 & 1,031 \\
\hline Min & -0.043 & -7.919 & 0.615 & -11.093 & -0.067 & -2.746 & -0.173 & -2.946 & -0.006 & -2.078 & 0.541 & 315 \\
\hline Max & -0.001 & -0.612 & 0.998 & -0.610 & 0.796 & 4.811 & 0.244 & 8.215 & 0.031 & 2.162 & 0.997 & 2,006 \\
\hline$t$-test & $-5.720^{a}$ & & $-5.352^{a}$ & & $2.145^{b}$ & & $3.904^{a}$ & & 0.110 & & & \\
\hline
\end{tabular}

${ }^{a}$ significant at the $1 \%$ level; ${ }^{b}$ significant at the $5 \%$ level; ${ }^{c}$ significant at the $10 \%$ level.

Going further, the average beta is lower than that derived from the single-index model being equal to 0.934 and significantly different from zero at the $1 \%$ level. Moreover, again the majority of the individual beta coefficients are significantly different from unity at the $10 \%$ level or better suggesting a non-full replication strategy followed by the managers.

So far, the multi-factor model does not give us any new insights into the pricing of bond ETFs. However, the estimates for the size, momentum and equity factor provide some new insights. In particular, the average s coefficient, which stands for the small minus large ETFs in terms of assets under management, is positive and equal to 0.048 while it is significant at the 5\% level. Moreover, 23 of the individual estimates are positive coefficients, of which 12 are significant at the $10 \%$ or better, and 15 negative estimates, of which 5 are significant. Overall, the results indicate the existence of a sufficient size effect on the performance of German bond ETFs, that is, the small ETFs tend to perform better than the large ones.

The results on the momentum factor are even more powerful than the results on the size factor. More specifically, the average w coefficient on the winners minus losers factor is equal to 0.049 being significant at the $1 \%$ level. In addition, there are 22 positive and significant $w$ estimates and 2 positive but non-significant whereas there are just 2 significantly negative estimates and 4 negative but insignificant. On the whole, the results indicate that the momentum effect plays a material role in the determination of bond ETFs' performance.

In general, the last set of estimates concerning the impact of equity sector on bond ETF returns are in line with our expectations about an inverse correlation between the two markets. The majority of d estimates standing for the return of $D A X$ index are negative. In particular, $26 d$ coefficients are negative but just 4 of them are significant. In addition, there are 12 positive estimates, 2 of which are significant. Overall, these results give us an indication of a negative relation between bond ETFs and the German stock market but the lack of statistical significance does not allow us to draw a solid inference about the impact of equity prices on the pricing of bond ETFs in Germany.

Finally, the average $R$-square equals 0.932 suggesting a high explanatory power of the model. Given the qualitative similarity in results concerning alphas and betas in the 
single and multiple factor models, we infer that both models can adequately explain the pricing of German bond ETFs.

\subsection{Risk-adjusted returns and persistence}

This section presents the risk-adjusted returns of ETFs and indexes in Table 5. Presented in the table are the Sharpe, Sortino, and Treynor ratios for each ETF and corresponding index. According to the results, the average Sharpe ratio of ETFs is negative and equal to -0.592 . The corresponding index is slightly better and equal to -0.577 . The relevant t-test applied on the difference in Sharpe ratios between ETFs and indexes indicates that the gap in risk-adjusted returns is statistically significant at the $10 \%$ level. Scanning through individual Sharpe ratios, we find that there are just 7 ETFs with higher Sharpe ratio than those of the indexes. Consequently, based on Sharpe ratios, we infer that the ETFs underperform the underlying indexes. are the Sharpe ratio, Sortino ratio and Treynor Ratio. $T$-test assesses whether the difference in performance rating between ETF and indexes is statistically significant.

\begin{tabular}{lcccccc}
\hline Symbol & \multicolumn{2}{c}{ Sharpe Ratio } & \multicolumn{2}{c}{ Sortino Ratio } & \multicolumn{2}{c}{ Treynor Ratio } \\
& ETF & Index & ETF & Index & -0.058 & -0.055 \\
\hline EUN4 & -0.297 & -0.293 & -0.426 & -0.426 & -0.033 & -0.031 \\
\hline EUN5 & -0.181 & -0.185 & -0.257 & -0.260 & -0.050 & -0.049 \\
\hline EUNR & -0.321 & -0.319 & -0.473 & -0.468 & -0.145 & -0.133 \\
\hline IBCD & -0.297 & -0.308 & -0.376 & -0.382 & -0.135 & -0.131 \\
\hline IBCS & -0.600 & -0.591 & -0.751 & -0.737 & -0.150 & -0.144 \\
\hline EXHE & -1.042 & -1.036 & -1.255 & -1.243 & -0.055 & -0.053 \\
\hline EUNT & -0.553 & -0.557 & -0.734 & -0.736 & -0.054 & -0.052 \\
\hline EUNS & -0.534 & -0.533 & -0.734 & -0.740 & -0.144 & -0.141 \\
\hline SLXX & -0.388 & -0.383 & -0.520 & -0.512 & -0.090 & -0.086 \\
\hline IUS6 & -0.431 & -0.427 & -0.550 & -0.546 & -0.106 & -0.105 \\
\hline IUS5 & -0.176 & -0.174 & -0.257 & -0.257 & -0.047 & -0.045 \\
\hline EUN3 & -0.097 & -0.096 & -0.151 & -0.149 & -0.054 & -0.052 \\
\hline EUN8 & -0.167 & -0.164 & -0.244 & -0.239 & -0.143 & -0.142 \\
\hline IBCN & -0.707 & -0.707 & -0.878 & -0.877 & -0.140 & -0.138 \\
\hline IBCM & -0.411 & -0.408 & -0.579 & -0.577 & -0.152 & -0.151 \\
\hline IBCA & -1.348 & -1.342 & -1.505 & -1.500 & -0.147 & -0.145 \\
\hline IBCL & -0.255 & -0.252 & -0.364 & -0.362 & -0.056 & -0.054 \\
\hline EUN9 & -0.254 & -0.249 & -0.364 & -0.358 & -0.155 & -0.153 \\
\hline IBCI & -0.451 & -0.448 & -0.607 & -0.603 & -0.079 & -0.070 \\
\hline EUN6 & -3.323 & -2.904 & -3.811 & -3.597 & -0.145 & -0.132 \\
\hline EXHA & -0.638 & -0.652 & -0.837 & -0.853 & -0.155 & -0.146 \\
\hline EXX6 & -0.242 & -0.236 & -0.343 & -0.333 & & \\
\hline & & & & & \\
\hline
\end{tabular}




\begin{tabular}{|c|c|c|c|c|c|c|}
\hline EXHD & -0.466 & -0.458 & -0.644 & -0.628 & -0.147 & -0.132 \\
\hline EXVM & -1.509 & -1.475 & -1.522 & -1.491 & -0.107 & -0.102 \\
\hline EXHG & -1.001 & -0.974 & -1.396 & -1.390 & -0.158 & -0.153 \\
\hline EXHH & -0.791 & -0.782 & -1.049 & -1.041 & -0.154 & -0.150 \\
\hline EXHB & -1.374 & -1.369 & -1.521 & -1.516 & -0.148 & -0.139 \\
\hline EXHC & -0.778 & -0.770 & -0.989 & -0.981 & -0.148 & -0.135 \\
\hline EXHF & -0.556 & -0.537 & -0.757 & -0.736 & -0.161 & -0.150 \\
\hline EXHK & -0.276 & -0.260 & -0.398 & -0.367 & -0.166 & -0.148 \\
\hline EXHJ & -0.499 & -0.482 & -0.695 & -0.671 & -0.159 & -0.150 \\
\hline INXG & -0.207 & -0.205 & -0.286 & -0.284 & -0.136 & -0.135 \\
\hline IGLT & -0.318 & -0.315 & -0.458 & -0.454 & -0.140 & -0.139 \\
\hline IUST & -0.272 & -0.268 & -0.368 & -0.365 & -0.138 & -0.134 \\
\hline IUSM & -0.244 & -0.243 & -0.358 & -0.357 & -0.133 & -0.132 \\
\hline IUSU & -1.098 & -1.102 & -1.265 & -1.270 & -0.151 & -0.149 \\
\hline IUS7 & -0.144 & -0.146 & -0.157 & -0.164 & -0.099 & -0.098 \\
\hline EUNH & -0.263 & -0.262 & -0.395 & -0.398 & -0.061 & -0.060 \\
\hline Average & -0.592 & -0.577 & -0.744 & -0.733 & -0.118 & -0.113 \\
\hline Min & -3.323 & -2.904 & -3.811 & -3.597 & -0.166 & -0.153 \\
\hline Max & -0.097 & -0.096 & -0.151 & -0.149 & -0.033 & -0.031 \\
\hline$t$-test & $-1.778^{c}$ & $-2.129^{b}$ & $-7.082^{a}$ & & & \\
\hline
\end{tabular}

${ }^{a}$ significant at the $1 \%$ level; ${ }^{b}$ significant at the $5 \%$ level; ${ }^{\text {c }}$ significant at the $10 \%$ level.

The results on the Sortino ratio are qualitatively equal to those of the Sharpe ratio. More specifically, the average ratio of ETFs and indexes are equal to -0.744 and -0.733 , respectively. In addition, the difference in Sortino ratios is significant at the $5 \%$ level. Further, there are 8 cases in which the ETFs have a little bit better risk-adjusted return than the indexes. Overall, the Sortino ratio reconfirms the underperformance of ETFs with respect to the market returns at the average level.

The results on the Treynor ratio do not alter the inferences drawn with the Sharpe and Sortino ratios. The average Treynor ratio of ETFs is equal to -0.118 and the respective ratio of the indexes is equal to -0.113 . The difference in these ratios is highly statistically significant at the $1 \%$ level. Moreover, there is not any individual Treynor ratio among all ETFs to exceed the corresponding figures of the indexes. Therefore, we infer once again that the ETFs deliver risk-adjusted returns that are inferior to those of the indexes.

Overall, the findings of the risk-adjusted returns are in line with the results of the raw returns and the regression analysis of ETFs' pricing. That is, no matter what the performance measurement is, ETFs have inferior returns relative to corresponding indexes. Given the passive nature of ETFs, this finding is not odd.

Apart from comparing the risk-adjusted returns of ETFs and indexes, in this section we also assess the persistence in ETFs' risk adjusted performance. Persistence is ex- 
amined at the short-term level with the usage of Sharpe ratios and the application for each single ETF of a time-series model in which quarterly Sharpe ratio estimates are regressed on their lagged values.

The regression results are presented in Table 6. Presented are the estimates of the model's $\kappa$ and $\lambda$ coefficients along with the relevant $t$-statistics, $R$-squares and number of observations. The average $\kappa$ is negative and equal to -0.533 , statistically significant at the $5 \%$ level. The average $\kappa$ of the model is close enough to the average Sharpe ratio reported in Table 5 and verifies once again the negative risk-adjusted returns achieved by the sample's ETFs.

\section{Table 6. Risk-adjusted return persistence results}

This table presents the results of a time series regression model in which the quarterly risk-adjusted return of German Fixed-Income ETFs expressed by Sharpe Ratio is regressed on the its lagged values. $T$-test assesses the significance of estimates. $N$ is the number of quarterly risk-adjusted returns available for each ETF.

\begin{tabular}{|c|c|c|c|c|c|c|}
\hline Symbol & $\kappa$ & $t$-test & $\lambda$ & $t$-test & $R^{2}$ & $N$ \\
\hline EUN4 & $-0.545^{c}$ & -2.079 & -0.956 & -0.928 & 0.147 & 8 \\
\hline EUN5 & -0.172 & -1.178 & 0.382 & 0.586 & 0.064 & 8 \\
\hline EUNR & $-0.356^{a}$ & -3.251 & -0.065 & -0.472 & 0.069 & 6 \\
\hline IBCD & $-0.121^{c}$ & -1.705 & $0.721^{\mathrm{a}}$ & 5.567 & 0.525 & 31 \\
\hline IBCS & $-0.180^{b}$ & -2.195 & $0.762^{\mathrm{a}}$ & 7.301 & 0.648 & 32 \\
\hline EXHE & -0.267 & -1.369 & $0.818^{a}$ & 6.931 & 0.686 & 25 \\
\hline EUNT & $-0.659^{a}$ & -4.472 & -0.092 & -0.854 & 0.196 & 6 \\
\hline EUNS & $-0.623^{a}$ & -6.317 & -0.077 & -1.130 & 0.298 & 6 \\
\hline SLXX & $-0.242^{a}$ & -2.994 & $0.531^{\mathrm{a}}$ & 4.030 & 0.394 & 28 \\
\hline IUS6 & $-0.384^{a}$ & -2.853 & 0.043 & 0.178 & 0.005 & 10 \\
\hline IUS5 & -0.083 & -1.471 & 0.207 & 1.145 & 0.158 & 10 \\
\hline EUN3 & $-0.141^{b}$ & -2.146 & -0.398 & -0.788 & 0.111 & 8 \\
\hline EUN8 & $-0.324^{a}$ & -2.769 & $-1.495^{\circ}$ & -1.647 & 0.404 & 7 \\
\hline IBCN & -0.187 & -1.198 & $0.671^{\mathrm{a}}$ & 5.109 & 0.668 & 17 \\
\hline IBCM & -0.113 & -1.131 & $0.657^{a}$ & 4.148 & 0.570 & 17 \\
\hline IBCA & -0.277 & -0.716 & $0.843^{a}$ & 3.831 & 0.704 & 19 \\
\hline IBCL & -0.039 & -0.846 & $0.727^{\mathrm{a}}$ & 5.550 & 0.444 & 17 \\
\hline EUN9 & -0.251 & -0.873 & 0.006 & 0.005 & 0.000 & 7 \\
\hline IBCI & -0.153 & -1.600 & $0.729^{a}$ & 4.753 & 0.557 & 21 \\
\hline EUN6 & $-7.237^{a}$ & -3.333 & -0.415 & -1.043 & 0.179 & 8 \\
\hline EXHA & $-0.182^{c}$ & -1.618 & $0.775^{a}$ & 4.421 & 0.604 & 32 \\
\hline EXX6 & $-0.155^{b}$ & -2.231 & $0.550^{a}$ & 3.219 & 0.353 & 22 \\
\hline EXHD & $-0.154^{c}$ & -1.933 & $0.714^{a}$ & 4.588 & 0.509 & 31 \\
\hline EXVM & $-5.464^{a}$ & -3.356 & -0.209 & -0.629 & 0.054 & 10 \\
\hline EXHG & -0.214 & -0.566 & $0.849^{a}$ & 6.329 & 0.728 & 18 \\
\hline EXHH & -0.154 & -0.885 & $0.826^{a}$ & 4.048 & 0.684 & 18 \\
\hline EXHB & -0.379 & -0.961 & $0.825^{a}$ & 3.552 & 0.678 & 31 \\
\hline
\end{tabular}




\begin{tabular}{lllllll}
\hline EXHC & -0.221 & -1.311 & $0.777^{\mathrm{a}}$ & 3.735 & 0.597 & 31 \\
\hline EXHF & -0.152 & -1.098 & $0.756^{\mathrm{a}}$ & 4.510 & 0.576 & 18 \\
\hline EXHK & $-0.141^{\mathrm{c}}$ & -1.649 & $0.598^{\mathrm{a}}$ & 2.861 & 0.353 & 18 \\
\hline EXHJ & -0.154 & -1.191 & $0.731^{\mathrm{a}}$ & 4.169 & 0.537 & 18 \\
\hline INXG & -0.031 & -0.829 & $0.739^{\mathrm{a}}$ & 4.123 & 0.729 & 17 \\
\hline IGLT & -0.085 & -1.160 & $0.673^{\mathrm{a}}$ & 3.037 & 0.581 & 17 \\
\hline IUST & -0.086 & -1.083 & $0.642^{\mathrm{a}}$ & 3.347 & 0.463 & 17 \\
\hline IUSM & -0.116 & -1.361 & $0.512^{\mathrm{b}}$ & 2.483 & 0.322 & 17 \\
\hline IUSU & -0.385 & -1.396 & $0.689^{\mathrm{a}}$ & 3.074 & 0.567 & 19 \\
\hline IUS7 & -0.047 & -0.380 & $0.610^{\mathrm{a}}$ & 2.784 & 0.463 & 12 \\
\hline EUNH & $-0.535^{\mathrm{b}}$ & -2.136 & -1.182 & -1.079 & 0.225 & 7 \\
\hline Average & $\mathbf{- 0 . 5 5 3}$ & $\mathbf{- 1 . 8 3 3}$ & $\mathbf{0 . 3 5 5}$ & $\mathbf{2 . 6 5 4}$ & $\mathbf{0 . 4 1 7}$ & $\mathbf{1 7}$ \\
\hline Min & $\mathbf{- 7 . 2 3 7}$ & $\mathbf{- 6 . 3 1 7}$ & $\mathbf{- 1 . 4 9 5}$ & $\mathbf{- 1 . 6 4 7}$ & $\mathbf{0 . 0 0 0}$ & $\mathbf{6}$ \\
\hline Max & $\mathbf{- 0 . 0 3 1}$ & $\mathbf{- 0 . 3 8 0}$ & $\mathbf{0 . 8 4 9}$ & $\mathbf{7 . 3 0 1}$ & $\mathbf{0 . 7 2 9}$ & $\mathbf{3 2}$ \\
\hline $\boldsymbol{t}$-test & $\mathbf{- 2 . 6 2 3 ^ { \mathrm { b } }}$ & & $\mathbf{3 . 1 8 2 ^ { \mathrm { a } }}$ & & & \\
\hline
\end{tabular}

${ }^{a}$ significant at the $1 \%$ level; ${ }^{b}$ significant at the $5 \%$ level; ${ }^{\text {c }}$ significant at the $10 \%$ level.

The average $\lambda$ is equal to 0.355 , statistically significant at the $1 \%$ level. The average indicates strong persistence in the negative risk-adjusted return of ETFs. The single betas verify this inference. In particular, the model provides 29 positive $\lambda$, of which 25 are significant at the $5 \%$ level or better, and 9 negative $\lambda$, of which just 1 is significant. Negative $\lambda$ indicates a reversal in the performance of ETFs.

Measuring the model's ability to assess performance persistence, the average $R$-square is sufficiently high at 0.417 . Yet, the individual $R$-squares spread to a wide range with extreme values between 0.000 and 0.729 . The low $R$-squares mainly concern ETFs quarterly Sharpe ratio observations of low frequency.

\subsection{Tracking Error's measurement and persistence}

The last issue examined in this study concerns the tracking error of German fixed-income ETFs' return in relation to the return of the underlying bond index portfolios. Tracking error is measured via three alternative methods, namely the standard deviation in daily return differences $\left(T E_{1}\right)$, the standard errors obtained from the performance regression of ETF returns on index returns $\left(T E_{2}\right)$, and a semi-variance analysis of return differences $\left(T E_{3}\right)$.

The results of the applied methods are presented in Table 7. According to the results, the average $T E_{1}$ is equal to $0.062 \%$, statistically significant at the $1 \%$ level. Individual tracking error measures range from $0.010 \%$ at the lowest to $0.218 \%$ at the highest. Moreover, the average $T E_{2}$ is essentially equal to $T E_{1}$. The similarity between $T E_{1}$ and $T E_{2}$ is not surprising since the beta of ETFs, though it is statistically different from unity, it does approximate it. According to Pope and Yadav (1994), the two methods 
derive similar tracking error estimates when the portfolio's systematic risk stands close to unity. On the question of $T E_{2}$ 's extreme scores, Table 7 reports a minimum value of $0.010 \%$ and a maximum value of $0.215 \%$. In both $T E_{1}$ and $T E_{2}$, the lowest and highest records concern the same ETFs. This is also the case for the third method used to estimate tracking error, which derives a minimum and a maximum value of $0.009 \%$ and $0.200 \%$, respectively, whereas the average $T E_{3}$ is equal to $0.058 \%$.

\section{Table 7. Tracking error}

This table presents the estimations of German Fixed-Income ETFs' tracking error, which reflects the deviation in returns between ETFs and indexes. We apply three alternative methods in tracking error estimating, labeling them as $T E_{1}, T E_{2}$, and $T E_{3}$ $T E_{1}$ is the standard deviation of return differences between ETFs and indexes. $T E_{2}$ is the standard errors of ETFs' performance regression. $T E_{3}$ derives from a semivariance analysis of return differences between ETFs and indexes. T-test assesses the significance of tracking error estimates.

\begin{tabular}{|c|c|c|c|c|}
\hline Symbol & $T E_{1}(\%)$ & $T E_{2}(\%)$ & $T E_{3}(\%)$ & Average $T E_{(1+2+3)}(\%)$ \\
\hline EUN4 & 0.041 & 0.041 & 0.042 & 0.041 \\
\hline EUN5 & 0.070 & 0.070 & 0.063 & 0.068 \\
\hline EUNR & 0.031 & 0.031 & 0.032 & 0.031 \\
\hline IBCD & 0.218 & 0.215 & 0.200 & 0.211 \\
\hline IBCS & 0.042 & 0.042 & 0.039 & 0.041 \\
\hline EXHE & 0.035 & 0.035 & 0.034 & 0.035 \\
\hline EUNT & 0.030 & 0.030 & 0.031 & 0.030 \\
\hline EUNS & 0.026 & 0.026 & 0.026 & 0.026 \\
\hline SLXX & 0.046 & 0.046 & 0.046 & 0.046 \\
\hline IUS6 & 0.052 & 0.051 & 0.052 & 0.052 \\
\hline IUS5 & 0.069 & 0.069 & 0.066 & 0.068 \\
\hline EUN3 & 0.126 & 0.124 & 0.126 & 0.125 \\
\hline EUN8 & 0.049 & 0.049 & 0.039 & 0.046 \\
\hline IBCN & 0.024 & 0.024 & 0.020 & 0.023 \\
\hline IBCM & 0.041 & 0.041 & 0.033 & 0.038 \\
\hline IBCA & 0.010 & 0.010 & 0.009 & 0.010 \\
\hline IBCL & 0.059 & 0.059 & 0.047 & 0.055 \\
\hline EUN9 & 0.043 & 0.043 & 0.032 & 0.039 \\
\hline IBCI & 0.048 & 0.048 & 0.041 & 0.046 \\
\hline EUN6 & 0.017 & 0.011 & 0.016 & 0.015 \\
\hline EXHA & 0.095 & 0.094 & 0.094 & 0.094 \\
\hline EXX6 & 0.155 & 0.151 & 0.146 & 0.151 \\
\hline EXHD & 0.119 & 0.116 & 0.117 & 0.117 \\
\hline EXVM & 0.016 & 0.015 & 0.014 & 0.015 \\
\hline EXHG & 0.020 & 0.020 & 0.020 & 0.020 \\
\hline EXHH & 0.028 & 0.028 & 0.027 & 0.028 \\
\hline EXHB & 0.035 & 0.034 & 0.035 & 0.035 \\
\hline EXHC & 0.070 & 0.069 & 0.070 & 0.070 \\
\hline EXHF & 0.070 & 0.068 & 0.068 & 0.069 \\
\hline
\end{tabular}




\begin{tabular}{lllll}
\hline EXHK & 0.178 & 0.169 & 0.177 & 0.175 \\
\hline EXHJ & 0.066 & 0.064 & 0.062 & 0.064 \\
\hline INXG & 0.035 & 0.035 & 0.032 & 0.034 \\
\hline IGLT & 0.028 & 0.028 & 0.025 & 0.027 \\
\hline IUST & 0.080 & 0.079 & 0.073 & 0.077 \\
\hline IUSM & 0.072 & 0.072 & 0.064 & 0.069 \\
\hline IUSU & 0.023 & 0.023 & 0.020 & 0.022 \\
\hline IUS7 & 0.157 & 0.157 & 0.142 & 0.152 \\
\hline EUNH & 0.026 & 0.026 & 0.027 & 0.026 \\
\hline Average & $\mathbf{0 . 0 6 2}$ & $\mathbf{0 . 0 6 1}$ & $\mathbf{0 . 0 5 8}$ & $\mathbf{0 . 0 6 0}$ \\
\hline Min & $\mathbf{0 . 0 1 0}$ & $\mathbf{0 . 0 1 0}$ & $\mathbf{0 . 0 0 9}$ & $\mathbf{0 . 0 1 0}$ \\
\hline Max & $\mathbf{0 . 2 1 8}$ & $\mathbf{0 . 2 1 5}$ & $\mathbf{0 . 2 0 0}$ & $\mathbf{0 . 2 1 1}$ \\
\hline $\boldsymbol{t}$-test & $\mathbf{7 . 8 3 5 ^ { \mathrm { a } }}$ & $\mathbf{7 . 8 8 0 ^ { \mathrm { a } }}$ & $\mathbf{7 . 7 1 6 ^ { \mathrm { a } }}$ & $\mathbf{7 . 8 2 0 ^ { \mathrm { a } }}$ \\
\hline
\end{tabular}

${ }^{\text {a }}$ significant at the $1 \%$ level.

Overall, the applied investigation on tracking error shows that the German bond ETFs fail to exactly replicate the performance of the indexes they are designed to follow. This finding is in line with the results in the previous sections concerning raw returns, alphas and risk-adjusted returns, which generally revealed that the ETFs underperform the benchmarks. However, we should point out that though the magnitude of tracking error obtained from all the methods is significant, it is not very large, both at the average and at the individual level. In Table 8 we present the short-term persistence of tracking error. The table includes the constant and slope coefficients, the $t$-statistics, the $R$-squares and the number of quarterly tracking error observations. We note that persistence is only examined with the usage of the first tracking error method.

\section{Table 8. Tracking error persistence results}

This table presents the results of a time series regression model in which the quarterly tracking errors of German Fixed-Income ETFs expressed by the standard deviation in return differences between ETFs and indexes is regressed on the its lagged values. $T$-test assesses the significance of estimates. $N$ is the number of quarterly tracking errors available for each ETF.

\begin{tabular}{lcccccc}
\hline Symbol & $\alpha$ & $t$-test & $\xi$ & $t$-test & $R^{2}$ & $N$ \\
\hline EUN4 & 0.003 & 0.523 & $0.669 \mathrm{a}$ & 6.974 & 0.907 & 8 \\
\hline EUN5 & $0.017^{\mathrm{b}}$ & 2.404 & $0.368^{\mathrm{a}}$ & 5.592 & 0.862 & 8 \\
\hline EUNR & 0.005 & 0.810 & $0.655^{\mathrm{a}}$ & 4.486 & 0.870 & 6 \\
\hline IBCD & $0.033 \mathrm{c}$ & 1.749 & $0.769^{\mathrm{a}}$ & 3.575 & 0.594 & 31 \\
\hline IBCS & $0.029^{\mathrm{a}}$ & 3.664 & 0.120 & 0.651 & 0.014 & 32 \\
\hline EXHE & $0.006^{\mathrm{b}}$ & 2.291 & $0.698^{\mathrm{a}}$ & 6.922 & 0.713 & 25 \\
\hline EUNT & 0.006 & 0.671 & $0.638 \mathrm{c}$ & 1.693 & 0.580 & 6 \\
\hline EUNS & $0.008^{\mathrm{a}}$ & 2.979 & $0.492^{\mathrm{a}}$ & 6.400 & 0.932 & 6 \\
\hline SLXX & $0.016^{\mathrm{a}}$ & 2.903 & $0.613^{\mathrm{a}}$ & 3.142 & 0.377 & 28 \\
\hline IUS6 & 0.024 & 1.252 & 0.388 & 1.154 & 0.160 & 10
\end{tabular}




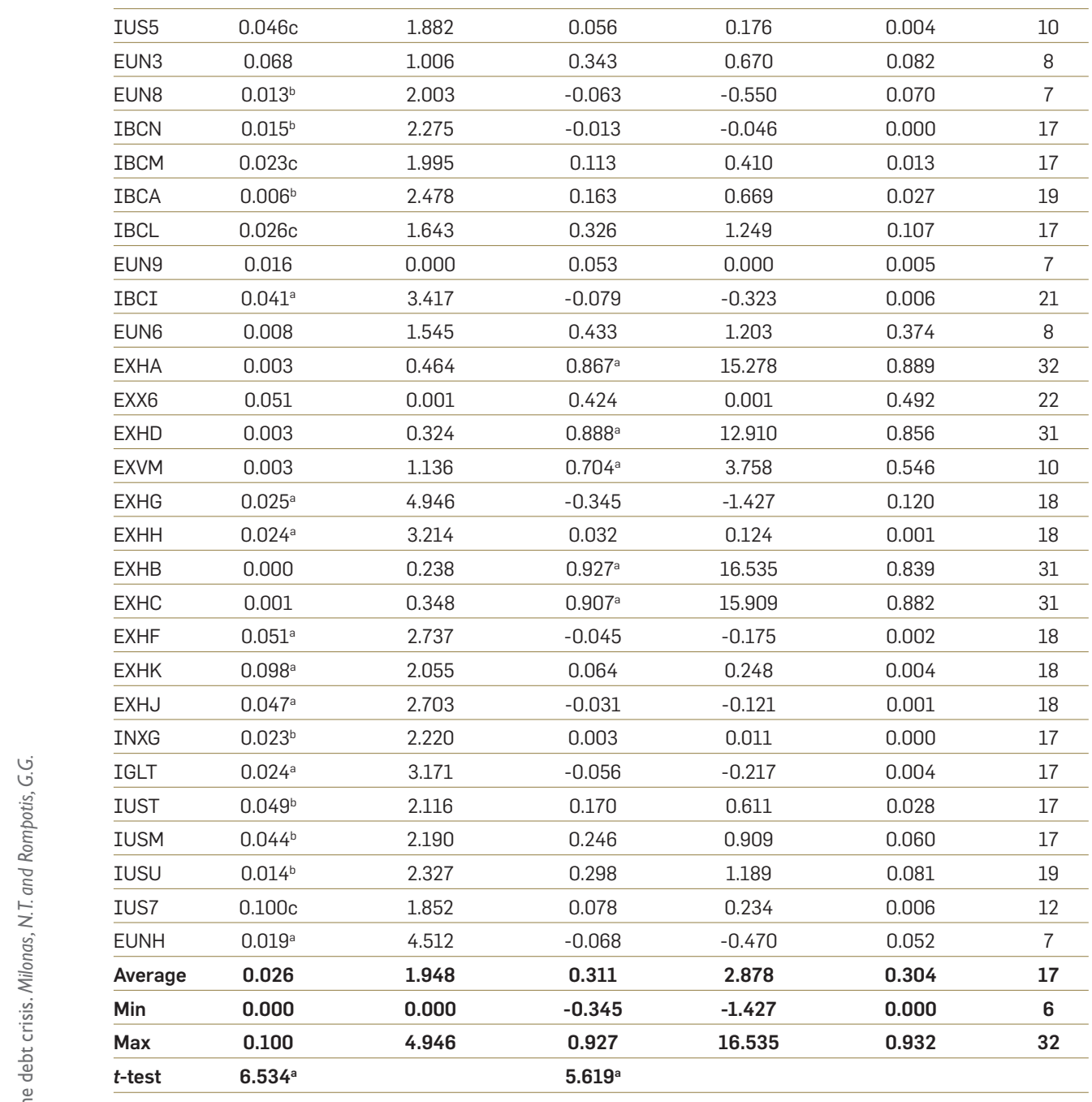

a significant at the $1 \%$ level; ${ }^{\mathrm{b}}$ significant at the $5 \%$ level; ${ }^{\mathrm{c}}$ significant at the $10 \%$ level.

The average coefficient derived from the model is equal to 0.026 , statistically significant at the $1 \%$ level. The average $\xi$ coefficient in Table 8 is positive as well and equal to 0.311 indicating strong persistence in tracking error, at least at a quarterly level. The majority of betas are positive (there are only 8 negative betas which do not statistically differ from zero), while 13 of them are highly statistically significant.

The validity of our results with respect to the persistence in tracking error is supported by the magnitude of the derived $R$-squares. On an average, $R$-square is equal to 0.304 ranging from 0.000 to 0.932 . 


\section{Conclusion}

In this article, we examine various issues concerning the performance and performance persistence of fixed-income ETFs, a fast growing market worldwide, using a sample of 38 Bond iShares traded in the German market. We chose to study the German fixed income ETFs for three reasons: First, the German market plays a leading role in Europe and is a major player in world markets in terms of capitalization and assets held. Second, it is the first extensive study on this type of ETFs in this market, and third, fixed income investments and their ETFs, in particular, are in the center of investment turmoil in the serious debt crisis that plagues Europe and threatens the world bond and stock markets.

To examine the pricing mechanism of bond ETFs we apply both single-index and multi-factor analysis. Both analyses reveal that have negative alphas. Negative alphas were expected given the passive investment strategy adopted by ETFs and the fact that the ETF returns are calculated free of expenses. We also found that systematic risk of ETFs is lower than unity suggesting a departure from a full replication strategy.

Another finding is the small size effect on the return of bond ETFs. In particular, there is sufficient statistical evidence that the small bond ETFs tend to outperform the large ones. Another finding is the momentum effect also found in other mutual fund studies.

To estimate the risk-adjusted return of ETFs, we utilized the Sharpe ratio, the Sortino ratio and the Treynor ratio. A comparison in risk-adjusted returns between ETFs and indexes reveals that ETFs underperform the indexes.

The last analysis of our study deals with tracking error of ETFs. Standard and nonstandard methods for tracking error computation are employed such as the standard deviation in return differences, the standard errors of performance regression and a measure based on a semivariance analysis of return differences. All three methods show that there is a statistically significant tracking error of $0.06 \%$ relating to the investment in German fixed-income ETFs. Furthermore, in the short-run there is significant persistence in tracking error suggesting a small departure from a full replication strategy.

Overall, our results are consistent with the findings of the literature concerning the traditional bond mutual funds. For instance, Maag and Zimmermann (2000) find that the German bond funds underperform their benchmarks. This is also the case for the U.S. bond funds as reported by Blake et al. (1993) and Elton et al. (1995), among others. Another contribution relates to the implementation of a multi-factor 
analysis on the pricing of bond ETFs. Our findings on the size and momentum effects on bond ETF returns are potentially very helpful for investors who have invested or are currently thinking of investing in these ETFs. Finally, our findings on strong persistence at the short-term level suggest that fixed income investors will be in a better position if they pursue asset allocation strategies.

\section{References}

Blake, C.R., Edwin J.E. and Martin J.G. (1993). The Performance of Bond Mutual Funds, Journal of Business, 66(3), pp. 370-403.

Bollen, N.P. and Jeffrey A.B. (2004). Short-Term Persistence in Mutual Fund Performance, Review of Financial Studies, 18(2), pp. 569-597.

Carhart, M.M. (1997). On Persistence in Mutual Fund Performance, Journal of Finance, 52(1), pp. 57-82.

Elton, E.J., Gruber, M.J. and Blake, Ch.R. (1995). Fundamental Economic Variables, Expected Returns, and Bond Fund Performance, Journal of Finance, 50(4), pp. 1229-1256.

Fama, E.F. and French, K.R. (1993). Common Risk Factors in the Returns on Stocks and Bonds, Journal of Financial Economics, 33(1), pp. 3-56.

Gruber, M.J. (1996). Another Puzzle: The Growth in Actively Managed Mutual Funds, Journal of Finance, 51(3), pp. 783-810.

Hendricks, D., Patel, J. and Zeckhauser R. (1993). Hot Hands in Mutual Funds: Short-Run Persistence of Relative Performance, 1974-1988, Journal of Finance, 48(1), pp. 93-130.

Huij, J. and Derwall, J. (2008). Hot Hands in Bond Funds, Journal of Banking and Finance, 32(4), pp. 559-572.

Maag, F. and Zimmermann, H. (2000). On Benchmarks and the Performance of DEM Bond Mutual Funds, Journal of Fixed Income, 10(3), pp. 31-45.

Mazzilli, P., Maister, D. and Perlman, D. (2008). Fixed-Income ETFs: Over 60 ETFs Enable Portfolios of Bonds to Be Traded Like Stocks, A Guide to Exchange Traded Funds and Indexing Innovations, Exchange Traded Funds, Institutional Investor, 7 , pp. 58-73.

Milonas, N.Th. and Rompotis, G.G. (2010). Dual Offerings of ETFs on the Same Stock Index: US vs. Swiss ETFs, Journal of Alternative Investments, 10(4), pp. 97-113.

Pope, F.P. and Yadav, P.K. (1994). Discovering Errors in Tracking Error, Journal of Portfolio Management, 20(2), pp. 27-32.

Rompotis, G.G. (2010). Penetrating Fixed-Income Exchange-Traded Funds. In Greg Gregoriou (Ed.), The Handbook of Trading, 1st ed. McGraw Hill, New York, pp. 213-231.

Rompotis, G.G. (2012). An Empirical Look at Swiss Exchange Traded Funds Market, AESTIMATIO, the IEB International Journal of Finance, 4, pp. 52-80. 
Silva, F., Cortez, M.C. and Armada, M.R. (2005). The Persistence of European Bond Fund Performance: Does Conditioning Information Matter, International Journal of Business, 10(4), pp. 341-362.

Sirri E.R. and Tufano, P. (1998). Costly Search and Mutual Fund Flows, Journal of Finance, 53(5), pp. 1589-1622. 